\title{
Objetos de ensino e o patrimônio cultural de ciência e tecnologia no Brasil e em Portugal: contribuições sobre levantamentos e inventários como instrumentos de preservação em escolas de ensino médio
}

Teaching objects and science and technology heritage in Brazil and Portugal: contributions from surveys and inventories as instruments for preservation in secondary schools

\section{MARCUS GRANATO'}

Museu de Astronomia e Ciências Afins / Rio de Janeiro, RJ, Brasil

\section{EMANUELA SOUSA RIBEIRO²}

Universidade Federal de Pernambuco / Recife, PE, Brasil

\section{VICTOR EMMANUEL TEIXEIRA MENDES ABALADA ${ }^{3}$}

Museu de Astronomia e Ciências Afins / Rio de Janeiro, RJ, Brasil

\section{BRUNO MELO DE ARAÚJO ${ }^{4}$}

Universidade Federal de Pernambuco / Recife, PE, Brasil

RESUMO: $O$ trabalho faz reflexões sobre o patrimônio cultural no âmbito das escolas de ensino médio, analisando algumas iniciativas de levantamentos e de valoração dos objetos de ensino enquanto bens culturais. Para tanto, buscamos traçar um perfil analítico de projetos de inventário desse patrimônio cultural no Brasil e em Portugal. A partir das lentes da ciência e tecnologia, utilizouse a revisão bibliográfica e os contatos com as instituições como metodologia para comparar

1. Pesquisador e Docente do curso de mestrado profissional em Preservação de Acervos da Ciência \& Tecnologia do Museu de Astronomia e Ciências Afins (Mast) e do Programa de Pós-Graduação em Museologia e Patrimônio da Universidade Federal do Estado do Rio de Janeiro (UniRio/Mast) e bolsista de produtividade $1 \mathrm{C}$ do $\mathrm{CNPq}$. Doutor em Engenharia Metalúrgica e de Materiais pela Universidade Federal do Rio de Janeiro (UFRJ). E-mail: <marcus@mast.br>

2. Docente do Departamento de Antropologia e Museologia e do Mestrado Profissional em Gestão Pública da Universidade Federal de Pernambuco (UFPE), e do Programa de Pós-Graduação em História da Universidade Federal Rural de Pernambuco (UFRPE). Doutora em História pela UFPE. E-mail: <emanuela.ribeiro@ufpe.br> 
3. Pesquisador e bolsista do Programa de Capacitação Institucional (PCI) do Museu de Astronomia e Ciências Afins (Mast). Doutor em História pela Universidade do Estado do Rio de Janeiro (Uerj). E-mail: <victoremmanuel@ mast.br>

4. Docente do Departamento de Antropologia e Museologia da Universidade Federal de Pernambuco (UFPE) e doutorando do Programa de Pós-Graduação em Museologia e Patrimônio da Universidade Federal do Estado do Rio de Janeiro (UniRio/Mast). E-mail: <brunomelodearaujo@ yahoo.com.br> o estado de pesquisas de inventário sobre estes objetos. Observou-se que as iniciativas aqui estudadas são assimétricas, necessitando ser padronizadas e aprofundadas de forma a alcançar as diferentes modalidades de ensino e, consequentemente, obter resultados mais consistentes e efetivos do ponto de vista da preservação. No entanto, percebe-se que existe um movimento crescente de identificação e preservação desses artefatos nos dois países.

PALAVRAS-CHAVE: Inventário. Patrimônio cultural da ciência e tecnologia. Patrimônio do ensino. Brasil. Portugal.

ABSTRACT: This study offers some reflections about cultural heritage in secondary schools, analyzing some initiatives to survey and enhance the value of teaching objects as cultural assets. An analytical profile of inventories of cultural heritage at secondary schools in Brazil and Portugal is presented. Considering the perspective of science and technology heritage, the methodology involved a literature review and direct contact with institutions to survey and compare the state of inventory-based research of such objects. The initiatives studied here were found to be asymmetrical, requiring standardization and more in-depth analysis to encompass different types of education, thus obtaining more consistent and effective results from a preservation perspective. Nonetheless, there is a growing movement to identify and preserve these artifacts in both countries.

KEYWORDS: Inventory. Science and technology heritage. Education heritage. Brazil. Portugal. 
Este trabalho se propõe a refletir acerca de inventários e levantamentos do patrimônio cultural no âmbito das escolas de ensino médio ${ }^{5}$ no Brasil e em Portugal, buscando identificar e analisar as iniciativas de valoração dos objetos de ensino enquanto patrimônio cultural de ciência e tecnologia (PCC\&T). Deste modo, os resultados aqui apresentados estão atrelados ao projeto de pesquisa "Patrimônio cultural luso-brasileiro de ciência e tecnologia: pesquisa, análise e acessibilidade"6 iniciado em 2014 e finalizado em 2018, que analisa os critérios de seleção utilizados em cada país para identificar os conjuntos de artefatos de interesse para este patrimônio; os valores atribuídos a esses conjuntos; a avaliação das coleções/ o diagnóstico nas vertentes de acessibilidade, conservação e documentação nos dois países; além de produzir um panorama sobre conjuntos de objetos candidatos a um possível inventário luso-brasileiro do PCC\&T.

$\bigcirc$ referido projeto e, consequentemente, este artigo realizam suas análises a partir dos estudos da museologia sobre o PCC\&T, e não do viés da história da educação, configurando assim um diferencial de abordagem que não se pretende qualitativo, mas apenas demarcador de interesses e, por conseguinte, de limites metodológicos. Esta perspectiva centrada na cultura material contempla desde a morfologia dos objetos até seu estado de conservação e exibição de registros da natureza e produção humana ou da comunidade de sentidos, permitindo identificar um amplo espectro de referências e atribuições simbólicas para evidenciar relações de pertencimento sobre determinado objeto, evento ou espacialidade.

A perspectiva da história da educação, como toda investigação histórica, questiona o passado a partir das demandas e inquietações do presente, e para tal pode utilizar os objetos como fonte de pesquisa. Da mesma forma que se preservam documentos em suporte de papel, preservam-se objetos a fim de serem utilizados como "estoques de informação"7 pela comunidade científica, ou até mesmo pela escolar. Contudo, vale salientar que em grande medida não é objetivo da história definir práticas de musealização de acervos, propiciar sua fruição e estabelecer critérios de gestão da informação e sua codificação em metalinguagens.

Zita Rosane Possamai ressalta inclusive que a história da educação passou por uma ampliação teórica-metodológica com a história cultural, debatendo novos temas e novas fontes, pois "a nova história cultural coloca ênfase na materialidade dos processos de produção, circulação e apropriação culturais, caracterizáveis a partir de uma atenção filigranática a micro transformações constitutivas de uma história". 8
5. Observamos que a denominação ensino médio, no Brasil, é relativamente recente, tendo sucedido uma série de outras nomenclaturas relativas ao mesmo segmento do ensino, como segundo grau e curso colegial. Foi fixada pela Lei de Diretrizes e Bases da educação Nacional (Brasil, 1996), sendo relativa ao estágio que se segue ao ensino fundamental e anterior ao ensino superior, constituindo, em muitos países, a etapa final da escolaridade obrigatória, em outras palavras, o ensino secundário, como é, hoje, denominado em Portugal. Assim, a exceção dos momentos em que for feita referência específica à organização do ensino em Portugal, e tendo consciência das complicações terminológicas da equiparação indistinta dos termos "educação secundária", "ensino secundário" e "ensino médio", ainda mais se levadas em conta suas especificidades históricas (Cf. Pessanha; Brito, 2013), o termo "ensino médio" passará a ser aqui adotado com o único propósito de padronização terminológica e facilitação do entendimento, uma vez que o artigo é escrito a partir de um ponto de vista brasileiro, em referência à organização atual do ensino.

6. Granato (2014).

7. Barreto (2000, p. 5).

8. Possamai (2015, p. 21). 
11. Cf. Araújo e Granato (2017).

12. Araújo, Ribeiro e Granato (2017, p. 13).
Segundo Agustín Escolano Benito, a história da educação em muitos de seus trabalhos busca entender os objetos como testemunhas de experiências e indicadores de práticas, componentes identitários de uma memória acerca da escolarização, ${ }^{9}$ bem como fatores importantes que permitem a compreensão da escola como um mercado consumidor que ganha força com a expansão escolar e a consequente difusão de um modelo que tinha no uso de artefatos um de seus pilares. ${ }^{10}$

De tal modo, por mais que o diálogo com o campo da história da educação seja imprescindível, seu foco é diverso daquele ligado aos estudos acerca do PCC\&T no campo da museologia e do patrimônio, que por sua vez procuram, por meio dos objetos, compreender e construir narrativas sobre a construção da ciência, - lugar e uso desses objetos em seus contextos, inclusive da própria ciência na sociedade. O fato do ensino científico se dar neste caso dentro da escola - mesmo sendo importantíssimo enquanto contexto que molda o conteúdo ensinado e fator indicativo e gerador de seu papel social - é de certo modo quase circunstancial: o interesse reside no estudo da produção e circulação do objeto e do saber científico e suas implicações socioculturais, não na compreensão do meio que o circunda stricto sensu, ou de como se dava a educação através do tempo e espaço. Assim, os aspectos enfocados nos estudos da história da educação não podem deixar de ser observados em qualquer empreitada séria concernente à temática, mas não constituem o fim último da abordagem aqui adotada, residindo aí a diferença crucial entre as perspectivas.

Compreendemos o PCC\&T como uma categoria complexa que abarca materialidades e subjetividades provenientes das dinâmicas científicas, dos conhecimentos produzidos, espaços de produção, reprodução de práticas e atribuição de valores e das representações que as coletividades fazem de si. ${ }^{11}$

A definição mais atual do patrimônio cultural da ciência e tecnologia compreende que este:

Constitui-se do legado tangível e intangível relacionado ao conhecimento científico e tecnológico produzido pela humanidade, em todas as áreas do conhecimento, que faz referência às dinâmicas científicas, de desenvolvimento tecnológico e de ensino, e a memória e ação dos indivíduos em espaços de produção de conhecimento científico. Estes bens, em sua historicidade, podem se transformar e de forma seletiva the são atribuídos valores, significados e sentidos, possibilitando sua emergência como bens de valor cultural. ${ }^{12}$ 
Apesar da ampla abrangência do PCC\&T, no projeto Patrimônio cultural luso-brasileiro... optou-se por trabalhar apenas com um recorte dessa definição: os objetos de ciência e tecnologia utilizados para as pesquisas e os desenvolvimentos tecnológicos em instituições das áreas das ciências exatas, da terra e engenharias.

$\bigcirc$ uso do termo "objeto de ciência e tecnologia" nesta delimitação não é casual, pois o modo como é mais comumente conhecido - instrumento científico - diz respeito apenas a um tipo de objeto: "é um termo complexo e que só se aplica em período histórico determinado (século XIX e início do século XX)". ${ }^{13}$ Assim, o termo instrumento científico se aplica

aos objetos que exploram um efeito, ou lei científica, [e é] conhecido para evidenciar uma grandeza observável relativamente a um sistema ou para modificar de forma controlada esse sistema. $\bigcirc$ uso do instrumento científico revela, qualitativa e quantitativamente, de modo direto ou indireto, através da medição, registro, processamento ou ainda através da imposição de condições aos limites controláveis ao sistema em estudo, características inicialmente desconhecidas do estado desse sistema. ${ }^{14}$

Já o termo objeto de ciência e tecnologia se aplica a objetos que podem ter sido utilizados em diversos contextos da produção da ciência e tecnologia.

Em virtude deste recorte tornou-se necessário pesquisar, além das instituições que tradicionalmente produzem conhecimento científico - como universidades e institutos de pesquisa -, aquelas que se relacionam com a produção desse conhecimento por meio do ensino e da pesquisa aplicada. Em projetos anteriores, realizados apenas no contexto brasileiro, ${ }^{15}$ dado que a pesquisa em escolas de ensino médio já havia se apresentado como uma frutífera possibilidade ainda aguardando ser melhor explorada, decidiu-se estender este recorte também para a pesquisa a ser realizada em Portugal.

A categoria do PCC\&T expressa uma abrangência capaz de incorporar os bens culturais provenientes da produção de conhecimento em escolas do ensino médio, tanto na perspectiva do patrimônio cultural das disciplinas da área da educação, quanto por abranger os instrumentos de demonstração e estudo de toda e qualquer área do conhecimento.

Dada a dimensão do artigo e o foco de interesse aqui explicitado, não consideramos oportuno aprofundar esta discussão epistemológica, e se chamamos atenção para este debate é apenas para enfatizar o caráter relacional do patrimônio cultural, que é sempre patrimônio de algo ou alguém. Assim, o PCC\&T se relaciona com o patrimônio do ensino, possuindo muitas intersecções não equivalentes, pois para que um bem se enquadre nessa categoria, ele precisa ser reconhecido como
13. Granato (2009, p. 79).

14. Cf. verbete "Instrumento científico" no portal Thesaurus de acervos científicos em língua portuguesa, disponível em: $<$ https://bit.ly/2q4WRCu> Acesso em: 6 abr. 2018.

15. Cf. Granato, Maia e Santos (2014). 
16. Pinheiro e Granato (2012, p. 31). vestígio de práticas da cultura científica, e diversos artefatos incluídos no patrimônio do ensino não seguem essa dinâmica.

Embora esta diferenciação pareça óbvia quando tratamos de objetos de ensino localizados em laboratórios de ciências naturais, de física ou de química, por exemplo, já não é tão simples quando identificamos troféus, medalhas e uniformes. Certamente os uniformes podem ser material de pesquisa das disciplinas da área da educação, embora a escola que os preserva não necessariamente thes atribui esse valor. Em geral, nos colégios, a preservação desses objetos representa a trajetória histórica da instituição, ou seja, é um patrimônio histórico, não sendo considerado PCC\&T pela comunidade que o detém.

Em se tratando de objetos que, na maioria das vezes, se encontram apenas "guardados" nas escolas, sem maiores investimentos em sua preservação, muitas vezes é o olhar do pesquisador que opta por identificar e, em alguma medida, instituir o próprio PCC\&T, em um processo consciente de patrimonialização. Tratase portanto de uma linha tênue, que depende muito dos agentes que selecionam e atribuem valor aos objetos. Esta constatação assim reforça a necessidade do reconhecimento e da reflexão acerca das iniciativas de valoração dos objetos de ensino enquanto bens culturais.

Ao mesmo tempo, é importante tratar das similaridades de abordagem, lembrando que os processos de patrimonialização permitem a formação e perenização de coleções e sua consequente disponibilização para a sociedade. Certamente historiadores e outros pesquisadores poderão "descobrir" e utilizar como fontes de pesquisa os objetos da cultura material "guardados" assistematicamente nas escolas, contudo será este processo que produzirá instrumentos para a preservação, que pode ser compreendida como

qualquer ação que se relacione à manutenção física desse bem cultural, mas também a qualquer iniciativa que esteja relacionada ao maior conhecimento sobre ele e sobre as melhores condições de como resguardá-lo para as futuras gerações. Inclui, portanto, a documentação, a pesquisa em todas as dimensões, a conservação e a própria restauração, aqui entendida como uma das possíveis ações para a conservação de um bem. ${ }^{16}$

Deste modo, as ações preservacionistas, tais como alguns dos projetos de levantamento e inventário do patrimônio cultural do ensino médio no âmbito de Brasil e Portugal que apresentaremos, acabam por estabelecer instâncias de preservação que possibilitam o futuro uso dos objetos em estudos e pesquisas, em uma atividade que ao mesmo tempo institui e cria sentidos. No que tange aos 
levantamentos dos dados apresentados, esta é uma discussão bastante pertinente, visto que as iniciativas de valoração dos objetos de ensino enquanto patrimônio cultural têm sido extremamente dependentes do olhar do pesquisador, conforme discutiremos à frente.

Do ponto de vista metodológico, os resultados apresentados sobre as escolas brasileiras, no âmbito do projeto "Valorização do patrimônio científico e tecnológico brasileiro", 17 seguiram a mesma metodologia geral do projeto, envolvendo visitas presenciais aos espaços selecionados; por outro lado, a revisão bibliográfica foi utilizada como forma de obter dados complementares e apresentar um panorama mais vasto dos trabalhos desenvolvidos no país, expondo questões e resultados relacionados a outros inventários realizados ou em andamento no território nacional. No caso das escolas portuguesas, a revisão bibliográfica permaneceu sendo a principal ferramenta de obtenção de informações, não apenas pela própria questão da distância geográfica e da dificuldade do acesso à informação, mas porque optamos por tratar apenas dos levantamentos e inventários que tiveram seus resultados publicizados nas plataformas acadêmicas ou governamentais. Esses dados, no entanto, foram contemporizados tanto pelo cruzamento dessas informações obtidas em diversos meios quanto por meio de sua comparação com outros dados obtidos via contatos virtuais com os próprios estabelecimentos de ensino portugueses - ainda que a falta de êxito de tais contatos tenha sido frequente, situação que é capaz de revelar, na própria incapacidade de obter-se um retorno, a atual conjuntura da realidade enfocada.

Consideramos importante também informar que alguns dos levantamentos e inventários desta pesquisa tratam de escolas que abarcam níveis para além do ensino médio. No entanto, buscou-se concentrar o foco apenas neste segmento para estabelecer mais firmes critérios comparativos entre Brasil e Portugal, pois naquele país são as escolas de ensino médio - segundo a terminologia brasileira - que concentram os objetos de ciência e tecnologia motivadores deste estudo. De modo ainda mais importante, dado o viés do PCC\&T, este recorte atende ao fato de que, historicamente, as disciplinas que mais utilizaram objetos de C\&T foram sendo introduzidas, nos dois países, através do ensino médio.

Por fim, como última informação de natureza metodológica, vale apontar outro aspecto do recorte realizado para este artigo: o perfil dos museus escolares. Ressalvamos que não é nosso interesse direto tratar deste tipo de instituição, por considerar que sobre os bens culturais já patrimonializados e/ou musealizados já incidem - pelo menos em tese - políticas e ações de preservação. Nosso interesse está voltado prioritariamente para o levantamento e inventário de objetos de C\&T ainda em processo de reconhecimento e seleção, portanto tratamos dos museus 
18. Instrumentos de demonstração e estudo são objetos ou associações de objetos cuja utilização permite, por meio da manipulação ou simples observação, evidenciar fenômenos ou leis físicas, estabelecer relações qualitativas entre grandezas físicas ou dar visibilidade a modelos, leis ou teorias. São utilizados para fins de estudo, ensino, divulgação ou recreação. Incluem modelos, maquetes, réplicas, aparelhos $\mathrm{e}$ modelos de máquinas simples e compostas (exemplos: modelo de locomotiva, aparelho de Haldat, balança aritmética, máquina de Atwood). Disponível em: <https://bit. ly/2q4WRCu>. Acesso em: 6 abr. 2018. escolares apenas para contextualizar as muitas possibilidades de abordagem desses objetos encontradas em escolas, ou quando os próprios achados fazem fortes referências a este tipo de museu.

Neste sentido, este artigo apresenta, inicialmente, uma seção que problematiza a preservação dos bens culturais em escolas, seja através de museus, seja através de coleções visitáveis. Visamos traçar um perfil da ausência de políticas preservacionistas na área e reforçar a importância das ações de levantamento e inventário dos bens culturais em escolas.

Na seção seguinte, buscamos definir e conceituar os inventários enquanto ações de preservação, situando-os no contexto de tais políticas públicas no Brasil e em Portugal, ao mesmo tempo em que apontamos a relevância dos indivíduos que selecionam os bens, além de seu possível reflexo nas políiticas públicas sobre qualquer categoria de bem cultural.

Finalmente, apresentamos as seções que tratam de alguns dos principais projetos de inventário do patrimônio cultural das escolas do ensino médio no Brasil e em Portugal. $\bigcirc$ artigo se encerra com um conjunto de considerações acerca do mapeamento dos inventários, comparando os trabalhos realizados nos dois países, não exatamente em termos quantitativos, mas na análise qualitativa das iniciativas identificadas, nas quais podemos constatar desde a diversidade de métodos e critérios até as capacidades de diálogo interdisciplinar e de visibilidade lacadêmica e social) desses projetos, necessárias para despertar outras atividades similares, bem como garantir sua continuidade.

\section{MUSEUS, MUSEUS ESCOLARES, COLEÇÕES VISITÁVEIS E OBJETOS DE CIÊNCIA E TECNOLOGIA EM ESCOLAS DO ENSINO MÉDIO}

A escola é um lugar repleto de elementos que remetem à produção de conhecimento e à aprendizagem. Alguns deles podem se transformar e mesmo incorporar outros sentidos, passando a ser considerados como patrimônio cultural. Trata-se, em geral, de objetos acumulados ao longo da trajetória dos colégios, das mais diversas procedências e áreas do conhecimento, englobando desde troféus, medalhas e uniformes até instrumentos de demonstração e estudo, ${ }^{18}$ amostras minerais, animais taxidermizados, vidrarias, modelos anatômicos, enfim, toda multiplicidade de itens que compuseram, ao longo do tempo, o dia a dia dessas instituições. 
Algumas escolas chegam a constituir museus ou coleções com a intenção de preservar este patrimônio, contudo a maior parte das instituições de ensino apenas mantém conjuntos de objetos "guardados" em armários, gavetas e mesmo em depósitos ou em espaços desativados, sem maior investimento em sua adequada preservação. Esta situação vem lentamente sendo modificada, na medida em que o próprio conceito e principalmente as práticas de patrimonialização se ampliam. Uma diversidade cada vez maior de bens adquire valor cultural, e os diversos grupos sociais constroem narrativas que atribuem sentido e valor a objetos e práticas cada vez mais recentes, configurando um "patrimônio contemporâneo", 19 conforme será discutido adiante.

As práticas de preservação variam de forma significativa, indo desde o reconhecimento comunitário até a proteção estatal, culminando em alguns casos com a institucionalização dos bens culturais em coleções visitáveis, musealizadas ou outras estruturas formais de preservação. No caso dos artefatos alvo dos levantamentos e inventários dos bens culturais provenientes de atividades de ensino, percebemos diversos níveis de seleção e organização dos objetos. Utilizamo-nos da categorização elaborada para os objetos de C\&T apresentada no Quadro 1 para visualizar os diferentes níveis de sistematização.
19. Poulot (2017, p. 107).

20. Brasil (2009).

21. Portugal (2004).

22. Brasil (2013)

Quadro 1 - Proposta de classificação de conjuntos de objetos de ciência e tecnologia.

\begin{tabular}{|l|l|}
\hline Denominação & Características \\
\hline $\begin{array}{l}\text { Grupo de objetos } \\
\text { de C\&T não } \\
\text { visitável }\end{array}$ & $\begin{array}{l}\text { Objetos de C\&T não organizados, que podem ter valor cultural e não passaram } \\
\text { por qualquer procedimento de documentação, conservação, pesquisa ou exposição. } \\
\text { Encontram-se inacessíveis ao público, podendo estar até mesmo abandonados. }\end{array}$ \\
\hline $\begin{array}{l}\text { Grupo de objetos } \\
\text { de C\&T visitável }\end{array}$ & $\begin{array}{l}\text { Objetos deliberadamente agrupados por serem considerados valiosos para cultura } \\
\text { científica e tecnológica com mínima organização, expostos ou acessíveis ao público, } \\
\text { mesmo que apenas sob marcação de visita. }\end{array}$ \\
\hline Coleção visitável & $\begin{array}{l}\text { Objetos que possuem tratamento especial, deliberadamente agrupados por serem } \\
\text { considerados valiosos para cultura científica e tecnológica. Estes foram submetidos a } \\
\text { uma ou mais atividades museológicas visando sua preservação, incluindo listagem, } \\
\text { inventário, organização em local adequado e/ou são utilizados em estudos e } \\
\text { pesquisas; são expostos ou acessíveis ao público, mesmo que apenas sob marcação } \\
\text { de visita. Não estão inseridos em instituições denominadas museus, seja de acordo } \\
\text { com o Estatuto dos Museus brasileiros ou com a Lei-Quadro portuguesa, }{ }^{21} \\
\text { legislações nas quais esta diferenciação é clara, ainda que a prática nesses países } \\
\text { possa turvar essas delimitações, com a reprodução e utilização de nomenclatura } \\
\text { inadequada para identificar espaços diversos. }\end{array}$ \\
\hline $\begin{array}{l}\text { Coleção } \\
\text { musealizada }\end{array}$ & $\begin{array}{l}\text { Objetos deliberadamente agrupados por serem considerados valiosos para a cultura } \\
\text { científica e tecnológica, sob guarda de um museu e submetidos a todas as etapas } \\
\text { de musealização, incluindo produção de inventário, pesquisa, documentação, } \\
\text { exposição, conservação, e são efetivamente enquadrados na definição brasileira de } \\
\text { "bens culturais musealizados".22 }\end{array}$ \\
\hline
\end{tabular}

Fonte: Adaptado de Santos (2014, p. 129). 
25. Braghini e Silva (2017, p. 259).
No que tange às coleções musealizadas, cumpre salientar que nem todos os museus se enquadram na definição acima e que possuem trajetórias e características bastante diversas, geralmente engendradas pela sua formação e vinculação institucional. Assim, os autodenominados museus, quando submetidos aos diversos olhares disciplinares, que direcionam diferentes perspectivas de abordagem, criam delimitações que extrapolam a definição legal disposta na Lei 1 1.904/2009, que define museus como

instituições sem fins lucrativos que conservam, investigam, comunicam, interpretam e expõem, para fins de preservação, estudo, pesquisa, educação, contemplação e turismo, conjuntos e coleções de valor histórico, artístico, científico, técnico ou de qualquer outra natureza cultural, abertas ao público, a serviço da sociedade e de seu desenvolvimento. ${ }^{23}$

A formação de coleções e/ou criação de museus pode ser observada em diferentes espaços, congregando elementos significativos para um grupo social e suas referências. $\bigcirc$ entendimento atual sobre o conceito de museu se amplia e abarca desde a ideia de um local específico (edifício) até a dimensão do território, da comunidade ou de espaços virtuais.

Estudos sobre museus em escolas vêm sendo realizados por diversas disciplinas, destacando-se a educação, a história da educação e a museologia. Em todas as áreas costuma-se utilizar o termo "museu escolar", muito embora a expressão seja polissêmica. Conforme explicam Marília Gabriela Petry e Vera Lúcia Gaspar da Silva, podemos distinguir esta acepção de duas formas, por meio das categorizações de museu escolar e pedagógico:

o primeiro [termo] - escolar -, alojado dentro das instituições educativas, deveria servir a professor e a alunos para a realização de estudos pautados no concreto, isto é, agregar um conjunto de objetos para tornar a aprendizagem intuitiva. $\bigcirc$ segundo - pedagógico caracteriza-se como um centro de formação para professores, onde seriam desenvolvidos, testados, apresentados e difundidos novos métodos, mobiliários e instrumentos didáticos. ${ }^{24}$

No tocante ao museu escolar em sua materialidade e espacialidade, Silva e Braghini, amparadas em extensa revisão bibliográfica, nos apresentam diversas qualificações alertando que "a ideia de museu ligada ao funcionamento das escolas qualifica o histórico de suas peças". ${ }^{25}$ Assim, encontramos esse termo associado a painéis, armários e conjuntos de objetos dispostos em sala de aula. 
Possamai, ao analisar a cultura material escolar, utiliza o termo "museus de educação", compreendendo que se existe uma diversidade tipológica, há no entanto características recorrentes entre os tipos de museu aqui apontados. ${ }^{26}$ Esta autora ressalta o potencial da materialidade dos museus escolares no âmbito da educação, que permite acessar aspectos curriculares e pedagógicos, ideias, práticas educativas, reformas educacionais levadas a cabo pelos Estados nacionais, possibilitando assim uma visão crítica dos contextos em que profissionais de educação exercem suas atividades.

Realizando pesquisa em um programa de pós-graduação em museologia, Vânia Maria Siqueira Alves considerou em seus estudos os museus escolares como "instituições que já contam com um espaço organizado, visando a preservação e a comunicação do seu patrimônio educativo escolar entre o qual estão coleções e objetos de C\&T". ${ }^{27}$ A autora também verificou que poucas foram as iniciativas de levantamento de museus escolares no país. Os resultados por ela apresentados não se pretendem suficientemente amplos para englobar a maioria dessas instituições no Brasil. Partindo de um conjunto de 115 museus escolares, foi verificado que grande parte destes se encontra na região Sul do país, seguida pela Sudeste, com destaque para os estados de São Paulo e Rio Grande do Sul. O levantamento realizado permitiu concluir que:

Entre os identificados em espaço escolar menos da metade dos museus foram criados com finalidades didáticas. São os museus de história natural que se situam num recorte temporal - final do século XIX aos anos 1960, aproximadamente, e museus de tecnologia, característicos do final do século XX e início do XXI. A maioria é composta por museus de história surgidos a partir dos anos 1970 com funções memorialísticas. No entanto, grande parte desses museus também conta com artefatos de ciência e tecnologia, principalmente da tecnologia educacional. ${ }^{28}$

Apesar dos muitos estudos e intensos debates sobre o conceito de museu escolar, ainda não há, e talvez possa não existir, uma abordagem hegemônica que englobe a polissemia dos artefatos que compõem a materialidade escolar no museu ou do museu na escola.

Felizmente, observamos contatos interdisciplinares que por um lado propiciam aprofundamento dos temas aqui debatidos, e por outro fortalecem e identificam as especificidades disciplinares. Há um movimento crescente de pesquisadores da história da educação ressaltando "o valor de reservatório patrimonial da memória da cultura material escolar, permitindo uma educação histórica dos sujeitos e dos coletivos", 29 conforme nos explica Diana Vidal, amparada em Benito. A autora ainda evidencia a dificuldade de incorporar a
26. Possamai e Paz (2017, p. 283-284).

27. Alves (2017, p. 310).

28. Alves (2017, p. 330).

29. Vidal (2017, p. 259-260). 
30. Vidal (2017, p. 260).

31. Brasil (2009).

32. Vidal (2017, p. 260).

33. Cf. Saavedra e Fustes (2005). cultura material escolar pela história da educação, dadas as mudanças estruturais das escolas, administrativas e curriculares, e a problemática dos objetos de uso pessoal que não permanecem nas instituições. Segundo Vidal:

\begin{abstract}
Esta crença no papel educativo do patrimônio material e imaterial tem dado suporte a iniciativas museológicas, tais como Centro Internacional de la Cultura Escolar (Ceince), organizado por Escolano na Espanha. Mas não apenas. Outras ações realizadas no mundo ibero-americano podem ser lembradas, como a defesa do Museu Vivo da Escola Primária, por Margarida Felgueiras, em Portugal; a criação do Museu da Escola, por Anamaria Casassanta Peixoto, ou do Museu da Escola Catarinense, por Vera Gaspar da Silva, ambos no Brasil, e do Museo de la Escuela, por Maria Cristina Linares, na Argentina, dentre muitos exemplos. Aqui, ainda, podemos incluir a preocupação com os arquivos escolares por parte de vários pesquisadores, como Maria João Mogarro, Rosa Fátima de Souza, Maria do Carmo Martins, Nádia Gaiofatto Gonçalves, André Paulilo, Maria Cristina Meneses, Carmem Sylvia Vidigal de Moraes, lomar Barbosa Zaia, dentre vários outros. ${ }^{30}$
\end{abstract}

É nítido que a valorização dos objetos enquanto vetores de uma educação histórica ocorre pela valorização e pelo fortalecimento dos estoques de informação proporcionados pela museologia e por disciplinas afins, por meio da criação de ferramentas técnicas e políticas para distribuição, acesso e gestão do conhecimento produzido e acumulado.

Do ponto de vista das políticas de preservação, interessa compreender que o nível de organização dos objetos tende a estar diretamente relacionado a sua integridade física. Apesar de muitos espaços se autodenominarem museus, suas práticas estão distantes dos requisitos básicos estabelecidos na Lei $n^{\circ}$ $11.904 / 2009,{ }^{31}$ configurando-se muito mais como coleções visitáveis ou grupos de objetos visitáveis. Em muitas instituições de ensino é difícil identificar os artefatos, sua localização, dimensão e estado de conservação, conforme já discutido por Vidal. ${ }^{32}$ Apesar desta fragilidade institucional, é nos museus que os artefatos tendem a ser mais bem preservados.

Em Portugal, a situação desses espaços é relativamente similar. Na década de 1990, um trabalho de Vicente Saavedra e Emilio Fustes $^{33}$ discutia um renascimento progressivo dos museus da educação em suas mais variadas denominações, conseguindo apontar 683 estabelecimentos do gênero ao redor do mundo, dos quais apenas cinco haviam sido identificados em Portugal. No entanto, os autores chamavam a atenção para o número elevado de projetos de museus do tipo que poderiam ou não vir a tornar-se realidade, demonstrando um ambiente propício para se pensar em expedientes do gênero. 
A transição para os anos 2000 foi acompanhada por um maior interesse no tema. Com escopo mais amplo do que o desta pesquisa - centralizado no ensino primário, mas não reduzido a ele -, e visando constituir uma rede de pesquisadores e profissionais atuantes no campo dos museus escolares, instituiu-se em 2001 a Rede de Investigadores em História e Museologia da Infância e Educação. No entanto, inicialmente dinamizada, em grande parte pela atuação da professora Margarida Louro Felgueiras, da Universidade do Porto, dificuldades cercearam em curto espaço de tempo sua atuação, de modo que a professora já em 2006 apontava o cenário como desanimador. ${ }^{34}$

A pesquisa acadêmica, tanto na área da museologia quanto na história da educação, também acompanhou esse interesse, produzindo estudos de caso ou análises qualitativas, ${ }^{35}$ com uma abordagem mais ampla e quantitativa acerca desses espaços nas escolas portuguesas, sendo levada a cabo apenas por dois trabalhos, até onde foi possível verificar.

primeiro, desenvolvido por grupo coordenado por António Nóvoa, se focou nos estabelecimentos que constituíam antigos liceus ou escolas técnicas, apresentando 26 dessas instituições que já possuíam projetos museológicos próprios ou em colaboração, demonstrando uma dinâmica de preservação e divulgação de seu patrimônio institucional. ${ }^{36} \bigcirc$ segundo trabalho, realizado por Maria Paula dos Santos com escopo mais abrangente e englobando também escolas de níveis anteriores ao ensino médio, apresentava um total de 39 escolas detentoras de espaços denominados museu, núcleo museológico ou sala de exposições, com origem e acervos diversos, além de ainda apontar a existência de projetos de estabelecimento de espaços similares em outras tantas instituições. ${ }^{37}$

Em ambos os casos, tanto quanto o próprio tempo, um processo de reforma do ensino e dos estabelecimentos físicos de ensino pode ter tornado muitos desses dados desatualizados ou inválidos, com o encerramento desses locais e a dispersão de seu patrimônio. De tal modo, apesar dos esforços perceptíveis em sua criação, assegurar a preservação dos objetos inclusive nos museus escolares é em si uma incerteza - mesmo já podendo ser encarada como um possível registro de sua existência -, dada a própria situação desses museus, que nem sempre são reconhecidos como tal ou continuam a receber atenção com as mudanças de diretores, professores e diretrizes de ensino.

Assim, os esforços mencionados tendem a centrar-se nos levantamentos e inventários da cultura material escolar não musealizada e sob risco de desaparecimento sem nenhum tipo de registro.
34. Cf. Costa (2006).

35. Podemos citar como exemplos dos trabalhos derivados do interesse renovado na interseção entre escola e museus, dentre outros, estudos realizados por Felgueiras (2011), Meneses (2003), Oliveira (2007) e Santos (2006).

36. Mogarro (2013, p. 73).

37. Cf. Santos (2003). 
38. Poulot (2017, p. 107).

39. Poulot (2017, p. 107).

40. Cf. Chuva (2012).

41. Ponte (2014, p. 244).

\section{INVENTÁRIOS COMO INSTRUMENTOS DE PRESERVAÇÃO}

Tratar dos instrumentos de preservação e pesquisa de bens culturais implica inicialmente distinguir os bens culturais que há quase dois séculos são objeto de políticas públicas de preservação daqueles que apenas muito recentemente vêm sendo considerados como tais. Dentre ambos destacamos o "patrimônio contemporâneo", que Dominique Poulot ${ }^{38}$ descreve enquanto "objetos identificados precisamente com a vanguarda histórica, como instrumentos ou fatores de progresso", e que ainda segundo o autor "é o caso das ferramentas da pesquisa científica". ${ }^{39}$

Enquanto bens inseridos no dia a dia da produção científica e tecnológica, esses objetos são criados, consumidos e descartados em instituições que têm pouca visibilidade e circulação de público em geral. Laboratórios, institutos de pesquisa, universidades e afins não costumam ser associados às instituições de preservação e memória tradicionais e, no contexto brasileiro, os museus de ciência são poucos e sua atuação é geralmente bastante segmentada. Antes de serem patrimonializados, os objetos de C\&T já são, de certa maneira, invisíveis e pouco presentes no cotidiano da população.

Por outro lado, as políticas públicas do patrimônio cultural no Brasil, e no Ocidente em geral, possuem uma trajetória de mais de um século na preservação de bens móveis e imóveis vinculados, em um primeiro momento, à construção de uma narrativa identitária para as nações, e mais recentemente também vêm sendo associados às narrativas identitárias de grupos minoritários ou desfavorecidos. ${ }^{40}$

Portugal, após o fim do Estado Novo (1933-1974), passou por um processo de formulação de políticas públicas que visavam cultivar e afirmar as identidades locais, pelo reforço das iniciativas patrimoniais autárquicas e de pequeno porte. Desde então,

assistiu-se ao surgimento desenfreado de unidades museológicas por todo o território. Se por um lado essas unidades museológicas poderiam desempenhar um papel crucial na salvaguarda e valorização dos patrimónios nacionais e locais, empiricamente reconhecemos que estas unidades museológicas são, na generalidade, de pequena ou muito pequena dimensão e com recursos muito diminutos, sentindo grandes dificuldades no desenvolvimento da sua atividade em prol da salvaguarda do património. ${ }^{41}$ 
Assim, apesar deste incremento na diversidade de bens culturais patrimonializados, podemos afirmar que ainda estamos longe de garantir ampla visibilidade e representatividade desses bens, tanto no Brasil quanto em Portugal, especialmente do patrimônio contemporâneo. Conforme afirma Paulo César Garcez Marins, ainda existem amplas áreas sem representação nas políticas públicas de patrimônio no Brasil:

O peso da tradição, e sobretudo de uma herança conceitual simultaneamente agregadora e segregadora, sintética e hierarquizadora, é parte constitutiva dessa mesma trajetória de patrimonialização, o que certamente não pode ser olvidado para um devir que seja pautado pelo equilíbrio dos agentes que compõem o país.

O desafio de incluir as referências patrimoniais dos "diferentes grupos formadores da sociedade brasileira" reconhecidos pela Constituição de 1988 permanece. Longe de estarmos numa situação em que o "abuso monumental", a "banalização do patrimônio" ou a "inflação patrimonial" (Debray, 1999; Heinich, 2009) possam ser aqui cogitadas, os 1.195 bens tombados no Brasil e os 38 bens registrados apenas começaram a cumprir a missão de representar a complexidade do país. ${ }^{42}$

No caso do PCC\&T, ambos os países têm uma representatividade institucional bastante reduzida, ${ }^{43}$ e no que tange ao patrimônio cultural das escolas de ensino médio, esta é praticamente nula.

Mesmo nas discussões acadêmicas da história da educação ${ }^{44}$ e da história da ciência, ${ }^{45}$ os bens deste patrimônio vêm sendo negligenciados em prol de outras fontes de pesquisa. Trata-se de bens culturais que não costumam ser identificados enquanto tais pela comunidade que os cerca, dada a dificuldade de visualizar nos objetos de C\&T o caráter de ancianidade que permeia os bens tradicionalmente reconhecidos como patrimônio, conforme explica Poulot:

Seguramente, a mediação é mais difícil, para dizer o mínimo, no caso de um bem patrimonial marcado pelo éthos do progresso, pelo culto à instrumentação expressamente escrita em linguagem matemática. $\bigcirc$ interesse por objetos científicos ultrapassados não foi alimentado por essa melancolia democrática tão intimamente ligada ao prazer dos museus desde o século passado, nem pela exaltação de uma continuidade consentida pela academia nem pelas metamorfoses próprias do campo artístico. ${ }^{46}$

Deste modo, em alguns casos, as ações de inventário de bens culturais terminam por não só constituir o patrimônio cultural, mas também por substituir a própria preservação física do bem. Eles
42. Marins (2016, p. 26).

43. Cf. Lourenço (2009) e Oliveira (2015).

44. Cf. Souza (2007)

45. Cf. Heering e Wittje (2012).

46. Poulot (2017, p. 108). 
47. Motta e Rezende (2016, p. 1).

48. Lima (2014, p. 4.339).

49. Cf. Ribeiro (2010).

50. Nakamuta (2006, p. 4).

51. De acordo com o International Council of Museums (Icom) e as polícias internacionais, os dados mínimos a serem registrados estão dispostos no Object ID, disponível em: $\quad<$ https://bit . ly/2CZMB76>. Acesso em: 25 abr. 2018. De acordo com o Instituto Brasileiro de Museus (Ibram), os dados mínimos a serem registrados são apresentados na Resolução Normativa $n^{\circ} 2 / 2014$, que "estabelece os elementos de descrição das informações sobre o acervo museológico, bibliográfico e arquivístico que devem ser declarados no Inventário Nacional dos Bens Culturais Musealizados, em consonância com o Decreto $\mathrm{n}^{\circ} 8.124$, de 17 de outubro de 2013" (Brasil, 2014). estão na origem da constituição do campo da preservação do patrimônio no século XVIII no contexto da construção dos Estados nacionais. Surgiram como modos de produzir um novo saber, por meio da coleta e sistematização de informações obedecendo a determinado padrão e repertório de dados passíveis de análises e classificações, e se constituem até hoje como instrumentos de identificação, valorização e proteção dos bens como patrimônio cultural. Nesse sentido, na trajetória das práticas de preservação, o conceito de inventário deve ser considerado chave, pois sempre remeterá à própria conceituação do que seja o patrimônio cultural. ${ }^{47}$

Neste sentido, o inventário resulta de seleção e atribuição de valor à cultura material, constituindo a patrimonialização de bens de maneira sistemática e continuada. Trata-se portanto de uma atividade realizada por técnicos e pesquisadores, cujos critérios e valores "operam estabelecendo mudanças de condição interpretativa para as manifestações da natureza e da cultura sobre as quais passam a atuar". ${ }^{48}$

Contudo, apesar de existirem enquanto mecanismos de preservação desde o início das práticas de patrimonialização dos Estados nacionais, os inventários não possuem uma metodologia padronizada, sendo construídos a partir de estratégias e interesses diversos e bastante influenciados por sua interação com os campos disciplinares que thes originaram. ${ }^{49}$

Enquanto ferramenta metodológica, o inventário

tem como objetivo o conhecimento real e sistemático dos bens e valores para salvaguarda e proteção, podendo-se consolidar em três tipos: inventários de identificação - meras listagens dos bens culturais, inventários científicos - instrumentos para se esgotar o conhecimento dos mesmos e tem uma função principalmente acadêmica, já os inventários de proteção - entende-se pela reunião dos dados suficientes para a proteção dos bens culturais. ${ }^{50}$

Deste modo, mesmo quando os autores aqui citados afirmam estar realizando "levantamentos", trata-se de inventários de identificação, que visam o reconhecimento preliminar e não conseguem abarcar as informações necessárias para garantir a salvaguarda material dos objetos. Ou, como em grande parte dos trabalhos aqui referenciados, trata-se de inventários científicos realizados para fins acadêmicos, que também, em sua maioria, não registram dados necessários para uma preservação efetiva. ${ }^{51}$ Em todos os casos, os resultados dependem das perguntas que se visam responder.

Desta forma, não podemos afirmar que a execução de um inventário, necessariamente, signifique um processo de valoração efetivo ou no amplo conhecimento dos bens que estão sendo identificados. Faz-se necessário conhecer o 
próprio instrumento de inventário aplicado para que se possam apreender corretamente os resultados alcançados. Assim, o estudo dos projetos de inventário do patrimônio cultural das escolas do ensino médio no âmbito de Brasil e Portugal permite que tenhamos uma melhor dimensão do que, de fato, vem sendo preservado, ou não.

\section{CAMINHOS TRILHADOS: LEVANTAMENTOS E INVENTÁRIOS NO BRASIL}

Há pelo menos duas décadas a história da educação se debruça sobre a cultura material de ensino no país. ${ }^{52}$ Entretanto a produção até recentemente priorizou, conforme já apontado, o viés de pesquisa histórica, sem aprofundar os estudos e as ações sobre as práticas de patrimonialização e os inventários de preservação. Mesmo quando o fez, o foco nem sempre recaiu sobre os objetos, interpretando essa cultura material de forma ampla e produzindo importantes inventários acerca dos documentos dos arquivos escolares, tal qual foi o caso do trabalho realizado na antiga Escola Normal de Campinas nos anos 2000, capitaneado por Maria Cristina Menezes. ${ }^{53}$ Maior preocupação com esta abordagem parece se não despertada, difundida pelo contato com instituições cuja finalidade é a preservação do patrimônio cultural.

O desenvolvimento do projeto de pesquisa "Valorização do patrimônio científico e tecnológico brasileiro", 54 coordenado pelo Museu de Astronomia e Ciências Afins (Mast), permitiu desde 2009 realizar em uma das suas frentes de pesquisa um levantamento nacional sobre os conjuntos de objetos de C\&T existentes em quatro tipologias de instituições: museus (MUS), universidades (IES), institutos de pesquisa (ICT) e escolas de ensino médio (IEM). Foram definidos dois cortes para delimitação do universo de instituições estudadas: um cronológico, incluindo todos os objetos produzidos até a década de 1960; e um por áreas de conhecimento, incluindo as ciências exatas e da terra e as engenharias. $\bigcirc$ primeiro caso se justificou em função de que à época de início dos levantamentos, os objetos de C\&T produzidos a partir da década de 1970 ainda poderiam ser encontrados em uso, em sua função original. $O$ segundo buscou incluir as áreas que delimitam a coleção principal do Mast, principalmente porque seria um enorme desafio abarcar todas as áreas do conhecimento, possibilitando inclusive que a iniciativa não chegasse a um resultado conclusivo e abrangente.

Como já mencionado em publicações relacionadas ao projeto, ${ }^{55}$ as escolas de ensino médio não foram priorizadas nos levantamentos em função de, nos primórdios do estudo, verificarmos que se tratava de um universo muito amplo em
52. Cf. Braghini e Silva (2017), Fiscarelli (2009), Silva e Petry (2012), Souza (2007) e Zancul (2018).

53. Cf. Menezes (2011).

54. Cf. detalhes do projeto, disponível em: $<$ https://bit. ly/2O2kzJ4>. Acesso em: 15 abr. 2018.

55. Cf. Granato et al. (2013), Granato, Maia e Santos (2014) e Granato e Santos (2015). 
$56.56 \%$ IES; $32 \%$ MUS; $11 \%$ ICT e 1\% IEM.

57. Granato e Santos (2015, p. 87).

58. Granato e Santos (2015, p. 88). relação ao número de instituições de interesse e por sua esparsa distribuiç̦ão pelo país, tornando o acesso a um número significativo de espaços visitados um imenso desafio. Ainda assim foram registradas algumas escolas que, por motivos variados, puderam ter seus dados coletados de forma mais simples.

Registramos que mesmo com a exclusão da maior parte das IEM do número de instituições a serem verificadas, partiu-se de 1.500 locais $^{56}$ nas diversas tipologias já mencionadas, que geraram 311 registros de conjuntos de objetos de C\&T de interesse. ${ }^{57}$ É importante destacar que, excetuando-se os MUS, o número das demais instituições pesquisadas e registradas pode, no decorrer do tempo, passar por flutuações, pois, por um lado, podem ocorrer descartes, e assim conjuntos registrados podem desaparecer; e, por outro, novos conjuntos podem ser formados, inclusive como efeito colateral das visitas presenciais realizadas pela equipe do projeto, trazendo uma nova forma de considerar os objetos de C\&T históricos.

Foram registradas no âmbito do projeto Valorização apenas onze IEM, restando um grande contingente a ser explorado. Apesar do número pequeno de instituições registradas, segundo Granato e Santos,

se calcularmos o número médio de objetos preservados por instituição em cada tipologia, teremos o seguinte panorama: 62 objetos por ICT; 110 objetos por IES; 154 objetos por MUS; 275 objetos por IEM. $\bigcirc$ resultado mostra o potencial significativo das IEM em guardar objetos de interesse, já que em oito instituições foram identificados mais de 2.000 artefatos. ${ }^{58}$

Percebe-se que à época da publicação dos dados mencionados, eram oito as IEM registradas, inicialmente gerando em média 275 objetos por instituição. Esses números foram atualizados para onze museus escolares, onde se encontram cerca de 7.000 objetos, ou uma média de 647 objetos por unidade. Considerando que o número total de objetos de C\&T identificados pelo projeto Valorização em todos os tipos de instituição pesquisadas no Brasil foi de cerca de 38 mil, o percentual relacionado somente às IEM registradas chega a mais de 19\%; número muito significativo e que estimula os levantamentos em nível nacional para esse tipo de instituição. É importante ressaltar que nesse momento os denominados "museus escolares" não foram registrados como MUS e sim como IEM, já que geralmente esses espaços não possuíam todos os objetos de interesse para o projeto, além de caber uma reflexão prévia mais aprofundada acerca do que se constituem esses espaços, o que fugia das prioridades definidas no projeto Valorização. Assim, os resultados e análises do projeto não tiveram o intuito de esgotar o panorama nacional sobre a situação dos objetos existentes nas IEM, mas sim de divulgar 
informações na maioria das vezes indisponíveis e mostrar o potencial e a importância desses conjuntos de objetos, ressaltando o risco elevado de descarte em que se encontram.

Os principais dados coletados das onze IEM registradas estão apresentados na Tabela 1 a seguir.

Tabela 1 - Dados sobre as Instituições de Ensino Médio registradas pelo projeto Valorização.

\begin{tabular}{|l|c|c|}
\hline \multicolumn{1}{|c|}{ Nome da instituição } & Local & $\begin{array}{c}\text { Objetos } \\
\text { encontrados }\end{array}$ \\
\hline Colégio das Damas da Instrução Cristã & Recife, PE & 5 \\
\hline Liceu Nóbrega de Artes e Ofícios & Recife, PE & 5 \\
\hline Colégio Salesiano Sagrado Coração & Recife, PE & 6 \\
\hline Colégio Ginásio Pernambucano & Recife, PE & 4.108 \\
\hline Colégio Estadual Professor Soares Ferreira & Barbacena, MG & 500 \\
\hline Colégio Pedro II, unidade escolar Centro & Rio de Janeiro, RJ & 1.000 \\
\hline Colégio Marista Arquidiocesano de São Paulo & São Paulo, SP & 800 \\
\hline Colégio Culto à Ciência & Campinas, SP & 209 \\
\hline Colégio Sagrado Coração de Jesus & Campinas, SP & 3 \\
\hline Escola Estadual Bento de Abreu & Araraquara, SP & 200 \\
\hline Colégio Anchieta & Porto Alegre, RS & 286 \\
\hline
\end{tabular}

No Rio de Janeiro destaca-se o Colégio Pedro II (unidade Centro) por número, valores atribuídos e representatividade dos objetos de C\&T lá existentes. Em Pernambuco e São Paulo encontramos o maior número de IEM registradas, quatro em cada estado. Em Pernambuco destaca-se o Colégio Ginásio Pernambucano e, em São Paulo, o Colégio Marista Arquidiocesano, por seu número de objetos de C\&T, respectivamente 4.108 e 800, e sua diversidade tipológica. A partir desta relação serão destacadas informações sobre o contexto e os objetos de C\&T ali existentes.

Colégio Damas, em Recife, é uma instituição de ensino privado fundada em 1896, cujo acervo de cinco objetos registrados são do Laboratório Oswaldo Cruz da escola. As peças foram adquiridas para fins educativos, sendo utilizadas pelos professores e alunos em aulas de ciências. Segundo informações da responsável pelo acervo, o número de objetos foi diminuindo por falta de uso ou por estarem obsoletos, sendo em sua maioria doados a museus e outras escolas. Os objetos restantes na instituição foram guardados pela professora de ciências, que os mantém em suas caixas originais e em ótimo estado de conservação. 
59. Pereira da Costa (1984, p. 283).
Também em Recife se situa o Colégio Salesiano Sagrado Coração, instituição de direito privado fundada em 1895, tendo sido equiparado ao Colégio Pedro ll em 1906, provável época de montagem dos seus laboratórios de ensino. Existem fotografias antigas que permitem identificá-los: Gabinete de História Natural do Colégio Salesiano, 1925; Gabinete de Mineralogia, 1910; Laboratório de Física, 1910 e 1925. Atualmente estes gabinetes e laboratórios não mais existem, tendo restado poucas evidências materiais deles, entre elas as seis peças que compõem o conjunto de objetos de C\&T registrado pelo projeto Valorização. $\bigcirc$ estado de conservação das peças é bom e o Colégio possui um conjunto de fotografias dos antigos espaços, que são a única referência concreta relativa ao acervo que não mais existe. Todos os laboratórios do Colégio foram modernizados.

Na mesma cidade, cabe mencionar o Colégio Nóbrega, fundado em 1917, ampliado em 1924 e 1933 e fechado em 2006. Seus cinco objetos remanescentes pertenceram a seu antigo laboratório, e no restante do acervo foi localizado um catálogo incompleto da Maison Deyrolle, fabricante de instrumentos de laboratório da época, datado de janeiro de 1934, provável data de constituição dos laboratórios. Há registros fotográficos de um grande gabinete de história natural e de um bem montado laboratório de física, provavelmente ainda em funcionamento na década de 1950. Como o Colégio foi fechado, atualmente a Companhia de Jesus, Província Brasil Nordeste, é responsável pelo espólio. As peças mais antigas localizadas são: um modelo anatômico (provavelmente da Maison Auzoux), um conjunto de lâminas de microscópio (com inscrição Maison Auzoux), duas estantes em madeira (provavelmente Maison Deyrolle) e um pássaro taxidermizado (provavelmente Maison Deyrolle), todas em mau estado de conservação.

Em Recife destacamos ainda o Colégio Ginásio Pernambucano. Fundado em $1^{\circ}$ de setembro de 1825 por meio de decreto do presidente da província de Pernambuco, José Carlos Mayrink, o Liceu Provincial de Pernambuco pode ser considerado das primeiras instituições de ensino do país. ${ }^{59} \mathrm{Em} 1842$ foi reestruturado, com modificações na grade curricular para adequação aos moldes do Colégio Pedro II, no Rio de Janeiro, referência para ensino no Império. Foram implementadas aulas práticas de ciências naturais em gabinetes estruturados para tal finalidade. $\bigcirc$ Colégio passou por várias mudanças de endereço no século XIX e há de se destacar a contribuição de Louis Jacques Brunet para a construção e consolidação do Museu de História Natural da instituição. No ano de 1998, o Ginásio Pernambucano foi novamente transferido, mas seu Museu permaneceu fechado no mesmo local, até a sua reabertura em 2012. Na ocasião, as coleções foram restauradas e documentadas, contando com um acervo de 4.108 objetos. Das coleções presentes podem ser identificadas peças procedentes da Alemanha, França e Itália, em sua maioria 
representações tridimensionais de espécimes botânicos, ou espécimes taxidermizados. Sobre este Colégio existem registros documentais em abundância para serem estudados, inclusive com registro da existência de gabinetes de ciências, gabinete de história natural, sala de ciências, museu de história natural, museu de ciências, laboratório de ciências biológicas, laboratório de física, laboratório de química, motivo pelo qual se manteve seus registros no escopo do projeto Valorização.

Em Minas Gerais, ${ }^{60}$ o único registro realizado foi o da Escola Estadual Professor Soares Ferreira, situada em Barbacena. Criada em 1890 pelo governador Bias Fortes com o nome de Gymnásio Mineiro, a instituição seguia o modelo do Colégio Pedro II. Em seus mais de 120 anos de trajetória, ela conseguiu preservar dois conjuntos de instrumentos de seus antigos laboratórios de física (trezentos objetos) e química (duzentos), que eram utilizados em suas aulas. Os objetos foram restaurados e são utilizados em demonstrações de ensino de ciências.

Na cidade do Rio de Janeiro encontra-se o Colégio Pedro II que, na unidade Centro, conta com laboratórios antigos de física e química, e já contou com um de história natural. $\bigcirc$ Colégio tem suas origens no Seminário São Joaquim, ${ }^{61}$ instituição destinada à criação de órfãos na primeira metade do século XVIII. Em 1837, uma reforma decretada por intermédio do regente interino do Governo Imperial, Pedro Araújo Lima, e do Ministro da Justiça e interino do Império, Bernardo Pereira de Vasconcellos, determina a mudança do nome do Seminário de São Joaquim para Colégio de Pedro II. 62 A data do decreto e o nome da "nova" instituição foram homenagens ao jovem príncipe e futuro imperador do Brasil, que completava naquele dia doze anos de idade. ${ }^{63} \bigcirc$ colégio se estruturou como referência para educação no país, sendo destinado a formar profissionais da sociedade para cargos públicos. A edificação da unidade Centro foi tombada em nível federal pelo Instituto do Patrimônio Histórico e Artístico Nacional (lphan) em 19 de maio de 1983.

Mast, percebendo a importância deste conjunto, desempenhou em parceria com o Colégio Pedro II um trabalho continuado de preservação ao longo de vários anos que envolveu, além da pesquisa de fontes, ações museológicas diversas como o registro dos objetos, sua higienização e a reorganização básica do laboratório de física, além do seu registro fotográfico inicial. Foi também produzido um inventário, e o acervo recebeu etiquetas de identificação. Os objetos se encontravam em diferentes estados de conservação, embora predominasse o mau estado, sendo armazenados em armários por área: ótica, mecânica e barologia, acústica, eletricidade, termologia. $\bigcirc$ número de artefatos de ensino existentes na unidade variou no tempo e algumas fontes apontam a ampliação do conjunto e o investimento do Colégio nesse tipo de artefatos para a instrução dos alunos, como um inventário de 1931 contendo aproximadamente 1.500 objetos do laboratório de física, e outro
60. Os dados relacionados a essa escola foram obtidos por visita realizada pela equipe coordenada pelo professor Gilson Nunes, da Universidade Federal de Ouro Preto, que participou do projeto Valorização.

61. Cf. Dória (1997).

62. Cf. Brasil (1837).

63. Cf. Granato e Santos (2014). 
64. Cf. Braghini, Piñas e Pedro (2014).

65. Braghini (2017, p. 287).

66. Cf. Meloni (2011, 2012, 2014).

67. Cf. Meloni (2015). de 1962, com 2.050 objetos. O laboratório hoje abriga uma coleção de cerca de mil objetos e existem alguns considerados raros, que foram utilizados no ensino de física em escola modelar para todas as demais do país.

Na cidade de São Paulo situa-se o Colégio Marista Arquidiocesano, instituição católica de direito privado e que vem sendo objeto de pesquisa e preservação de professores da Pontifícia Universidade Católica de São Paulo. ${ }^{64} \mathrm{~A}$ instituição tem suas origens no Seminário Episcopal de São Paulo, criado em novembro de 1856 para a formação de futuros padres católicos. Os Irmãos Maristas assumem o Colégio Diocesano a partir de 1908, já seguindo os padrões definidos pelo Colégio Pedro II, cuja equivalência somente seria obtida em 1932.65 Os cerca de oitocentos objetos ali existentes foram adquiridos entre 1850 e 1980 para o ensino de física e química. Na época do levantamento realizado pelo projeto Valorização não havia inventário das peças.

Na cidade paulista de Campinas encontra-se o Colégio Culto à Ciência, fundado oficialmente em 13 de abril de 1873, em sintonia com os ideais de progresso e do culto à razão característicos do século XIX. O estudo de seu acervo se deu de forma sistemática até 2009 por professores da Unicamp. ${ }^{66}$ Foram identificados 209 objetos, incluindo instrumentos e vidrarias. ${ }^{67}$ No entanto, o número é maior porque a opção foi considerar os materiais parecidos uma única vez. Por exemplo, há cerca de dez bicos de Bunsen diferentes, mas foi considerado apenas um para as finalidades de identificação e classificação. Desses objetos, pelo menos 77 instrumentos constam nos inventários de 1899 e 1902, mas seguramente há outros ainda não incluídos, porque foram encontrados após a sistematização das informações feita em 2009. Os demais instrumentos também foram adquiridos pela escola após 1902, provavelmente nas duas primeiras décadas do século XX. Praticamente todos os instrumentos que contém identificação dos construtores são de Émile Deyrolle ou de Lês fils d'Émile Deyrolle, e tinham como finalidade o ensino de física. Além desses, há alguns para o ensino de história natural (principalmente conservas de animais e em torno de cinquenta animais empalhados) e cerca de cinquenta frascos de reagentes desse período, mas poucos materiais típicos para o ensino de química, como vidrarias. As que resistiram ao tempo não contêm identificação.

Ainda em Campinas situa-se o Colégio Sagrado Coração de Jesus, fundado em 1909 por um grupo de irmãs Calvarianas. Nele se encontra o Observatório Astronômico Padre Jorge Polman, inoperante desde 2002 e reinaugurado em 17 de setembro de 2010. O prédio foi totalmente reformado, possuindo uma cúpula de $3 \mathrm{~m}$, e seu instrumento principal - um refrator Unitron de $100 \mathrm{~mm}$ - foi modernizado. O observatório é utilizado nas atividades com os alunos do próprio Colégio, porém abre em alguns eventos para o público em geral. Seu nome é uma 
homenagem a um dos grandes observadores e divulgadores da astronomia no Brasil. A luneta mais antiga da instituição é da década de 1950 e os objetos estão inventariados e em bom estado de conservação, alocados em uma pequena cúpula no último andar do prédio.

Em Araraquara encontra-se a Escola Bento de Abreu, criada em 1930 e registrada pelo projeto Valorização em função dos trabalhos ali desenvolvidos por Maria Cristina de Senzi Zancul, pesquisadora da Universidade Estadual Paulista, com a colaboração da Coordenação de Museologia do Mast. ${ }^{68}$ Essa iniciativa de preservação pode ser considerada uma das primeiras do país nesse tipo de espaço e resultou na organização, no registro e na conservação de duzentos objetos do laboratório da escola, utilizados no ensino de física.

Em Porto Alegre foi feito apenas um registro, de 286 objetos de C\&T do laboratório de física do Colégio Anchieta. ${ }^{69}$ Sua fundação data de 1890, pela ordem jesuíta, com nome Colégio dos Padres. $\bigcirc$ atual nome começou a ser utilizado em 1901. Com a expansão do centro de Porto Alegre, e também da instituição, houve a mudança para outro local em 1967, após treze anos de construções. As novas dependências ficavam na Avenida Nilo Peçanha, onde se encontra até hoje. Os deslocamentos e reformas nos ambientes provocaram algumas perdas de objetos de C\&T dos laboratórios. Em 1917, o Colégio inaugurou seu Museu de Ciências Naturais, cujo acervo histórico é constituído por instrumentos didáticos do laboratório de física, a maioria adquiridos no início do século XX por encomenda e oriundos sobretudo da Alemanha. Os objetos são incorporados ao acervo à medida que entram em desuso, devido ao surgimento de novos aparatos de ensino, e muitos ainda são utilizados em atividades de ensino como método comparativo aos instrumentos contemporâneos. São utilizados como objetos históricos e recentemente passaram a ser expostos ao público, embora só parte deles esteja inventariada. Além dos objetos de C\&T, podemos encontrar catálogos de fabricantes, livros de registros da Secretaria de Educação a partir de 1931 e levantamentos dos materiais presentes nos laboratórios. Os objetos estão em bom estado de conservação, embora alguns apresentem falta de peças. Possamai e $\mathrm{Paz}^{70}$ realizaram um estudo aprofundado sobre esse museu, comparando-o ao Museu Bernasconi de Buenos Aires, Argentina.

Além dos dados obtidos pelo projeto Valorização, cabe mencionar outras iniciativas que contribuem para a preservação do patrimônio do ensino no país. Zanculpl $^{71}$ apresenta resultados de levantamento de objetos antigos destinados ao ensino das disciplinas científicas nos primeiros ginásios do estado de São Paulo. A investigação incidiu sobre as 24 instituições em funcionamento em 1936, segundo as informações do Anuário de Ensino (1936-1937). De acordo com a autora,
68. Cf. Zancul (2009, 2010).

69. Os dados relacionados a essa escola foram obtidos por visita realizada pela equipe coordenada pela Profa. Maria Leticia Mazzuchi Ferreira, da Universidade Federal de Pelotas, que participou do projeto Valorização.

70. Possamai e Paz (2017, p. 285).

71. Cf. Zancul (2018). 
Vale ressaltar que, até 1930, existiam apenas três ginásios estaduais instalados: o Ginásio de São Paulo, na capital, criado em 1894, o Ginásio de Campinas, estabelecido em 1896, que teve sua origem como Colégio Culto à Ciência, em 1874 e o ginásio de Ribeirão Preto, de 1907.72

Duas das 24 instituições desse estudo, já foram aqui mencionadas a Escola Estadual Bento de Abreu, de Araraquara, e o Colégio Culto à Ciência, de Campinas. Segundo a autora, das 22 escolas restantes, dezesseis foram visitadas e as demais foram pesquisadas por contato telefônico e via internet. A situação dos conjuntos de objetos encontrados é muito variável, e em quatro escolas não foi encontrado nenhum objeto (Monteiro Lobato, em Taubaté; Barão de Survi, em Tatuí; Canadá, em Santos; Barão de Franca, em Franca). A Tabela 2 apresenta a seguir um resumo das informações coletadas por Zancul nas escolas onde foram identificados artefatos de interesse para as reflexões aqui realizadas.

Tabela 2 - Dados sobre as IEM registradas por Zancul (2018) em São Paulo.

\begin{tabular}{|l|c|c|}
\hline Nome das escolas estaduais & Local & Objetos encontrados \\
\hline Coronel Nhonhô Braga & Piraju, SP & algumas peças \\
\hline Otávio Ferrari & Itapeva, SP & algumas peças \\
\hline Coriolano Burgos & Amparo, SP & algumas peças \\
\hline Carlos Sampaio Filho & Penápolis, SP & 6 \\
\hline Valentim Gentil & Itápolis, SP & algumas peças \\
\hline Ernesto Monte & Bauru, SP & 7 \\
\hline $\begin{array}{l}\text { Cel. Cristiano Osório de } \\
\text { Oliveira }\end{array}$ & São João da Boa Vista, SP & 6 \\
\hline Dr. Cesário Coimbra & Araras, SP & \\
\hline São Paulo & São Paulo, SP & algumas peças \\
\hline Regente Feijó & Itu, SP & algumas peças \\
\hline Otoniel Mota & Ribeirão Preto, SP & algumas peças \\
\hline Plínio Rodrigues de Moraes & Tietê, SP & várias peças \\
\hline Barão do Rio Branco & Catanduva, SP & várias peças \\
\hline Dr. Washington Luís & Mogi das Cruzes, SP & várias peças \\
\hline $\begin{array}{l}\text { Dr. Júlio Prestes de Albuquer- } \\
\text { que }\end{array}$ & Sorocaba, SP & grande quantidade de peças \\
\hline Euclides da Cunha & São José do Rio Pardo, SP & grande quantidade de peças \\
\hline Cel. João Cruz & Avaré, SP & grande quantidade de peças \\
\hline Dr. Aurélio Arrobas Martins & Jaboticabal, SP & grande quantidade de peças \\
\hline
\end{tabular}


A autora conclui que a situação é crítica na maioria dos locais, cujos objetos ainda existentes estão em alto risco de perda, e complementa que as escolas sozinhas não darão conta de mais essa atividade de preservação.

Destaca-se ainda os trabalhos realizados com Escolas Técnicas (Etec), em uma iniciativa de professores do Grupo de Pesquisas em Memória e História da Educação Profissional que remonta há mais de dez anos, centrada em São Paulo e coordenada por Maria Lucia Mendes de Carvalho, ${ }^{73}$ cujos resultados podem irradiar e dialogar com o resto do Brasil. Desde 2014 este grupo estuda a cultura material existente nos centros de memória ou nos acervos escolares das Etec, incentivando a produção de inventários de objetos de C\&T e documentos textuais e iconográficos relacionados à materialidade disponível. No entanto, dada a especificidade histórica da organização do ensino técnico no país, optou-se neste artigo por não se aprofundar em tais instituições. ${ }^{74}$

De forma semelhante, temos uma série de estudos voltados para as Escolas Normais ${ }^{75}$ que, ao se debruçarem sobre diferentes materiais escolares (cadernetas, livros, provas, mobiliários), trazem novas contribuições à historiografia da educação e permitem alcançar novas dimensões do processo pedagógico. ${ }^{76} \mathrm{Um}$ exemplo é o levantamento da materialidade da Escola Normal Caetano de Campos, cujo acervo está sob a guarda da Fundação para o Desenvolvimento da Educação, da Secretaria de Educação do Estado de São Paulo, e vem sendo tratado pelo Núcleo de Referência em Memória da Educação, e potencialmente detém ricos espólios.

Os resultados aqui apresentados mostram a ponta do iceberg constituído pelo patrimônio que está hoje nas escolas de ensino médio no país. Trata-se de um panorama parcial, mas que permite descortinar o desafio adiante, pois se configura como uma situação emergencial na qual itens que podem constituir patrimônio estão em alto risco de perda e que, como já mencionado por diversos autores, não será resolvida pelas próprias escolas sem auxílio e sem que haja uma iniciativa nacional em vista do grande universo de espaços que precisam ser identificados e apoiados. Novamente, assim como no caso do PCC\&T, percebe-se a falta de uma política nacional para o patrimônio que considere essas novas tipologias e que viabilize formas de financiamento e preservação do que for considerado significativo tanto para as atuais quanto para as futuras gerações.
73. Cf. Carvalho (2017).

74. Como exceção temos o Colégio Pedro II, que de acordo com a Lei $\mathrm{n}^{\circ} \quad 11.892 / 2008$, é equiparado aos Institutos Federais de Educação, Ciência e Tecnologia.

75. Cf. Fiscarelli (2006), Funari (2005) e Xavier e Marques (2006).

76. Cf. Corrêa (2013). 
Em Portugal, levantamentos de PCC\&T com uma metodologia definida em âmbito nacional não foram realizados até os anos 2000, apesar da pioneira iniciativa de Mário Silva no crepúsculo do Estado Novo, quando da criação do Museu Nacional de Ciência e Técnica em 1976. O espaço não funcionou regularmente, e após sua extinção teve seu acervo incorporado à Universidade de Coimbra, em 2012, o qual abrigava coleções de física, medicina, indústria gráfica, computação, alfaias agrícolas, química, dentre outras, tendo sido reunido graças ao primeiro levantamento de identificação de material técnico e científico realizado em âmbito nacional ${ }^{77}$ - uma iniciativa pioneira em nível mundial.

Apesar de fragilidades decorrentes da falta de um maior rigor teóricometodológico em sua execução, é de se ressaltar o escopo desse extensivo levantamento, que buscou objetos representativos do desenvolvimento da ciência e da técnica em diversas instituições - não apenas universidades, como focaram muitas das primeiras empreitadas em outros países, que a partir de fins da década de 1980 o seguiram -, na tentativa de criar mecanismos de controle, identificação e visibilidade aos objetos.

Um levantamento específico e de caráter nacional só começou a ser realizado em Portugal com o projeto Patrimônio cultural luso-brasileiro que, em fase de conclusão, pesquisa o PCC\&T existente em ambos os países para estabelecer comparações entre ambos. Para tal, utiliza-se dos dados obtidos no Brasil pelo projeto Valorização, seguindo igualmente seus cortes temporal e de áreas do conhecimento, bem como adaptando sua metodologia. Se isso consequentemente significa que o projeto realiza o primeiro levantamento contemporâneo em escala nacional do PCC\&T em Portugal, o fato de ser desenvolvido por brasileiros e baseado no Brasil - ou seja, à distância, com impossibilidade de visitas presenciais, limitação de informações e barreiras culturais e conceituais a serem transpostas e/ ou problematizadas -, igualmente representa limitações e lacunas tanto em sua gama de atuação quanto nos resultados.

Neste sentido, os dados obtidos devem ser encarados mais como um panorama geral e uma fonte de problematizações do que como subsídios altamente precisos para medidas de preservação. Do mesmo modo, tais limitações ressaltam sua dependência de trabalhos anteriores realizados em terras lusas, em geral de escopo menor, a partir dos quais foram coletadas informações a terem sua atualidade verificada. 
De tal maneira, se o projeto Valorização não priorizou as instituições de ensino secundário pela amplitude da matéria, os trabalhos já realizados em história da educação fizeram que ele não se reproduzisse na análise desta categoria em Portugal. No entanto, mesmo iniciativas mais completas e focadas no âmbito nacional custaram a produzir um quadro geral bem delineado, não apenas por pensarem no patrimônio do ensino de forma mais abrangente sem focar nos objetos de C\&T, mas também por não abarcarem estabelecimentos de grande importância para a história do ensino em Portugal, e consequentemente para a história (do ensino) das ciências no país.

É o caso particular do projeto "Inventário e digitalização do património museológico da educação", levado a cabo pela Secretaria Geral do Ministério da Educação a partir de 2003, cujo ambicioso intuito era disponibilizar todo o espólio de natureza arquivística, documental e museológica do Ministério on-line. Algumas ausências - como o antigo Liceu de Ponta Delgada, atual Escola Secundária Antero de Quental, primeiro liceu a pedir em 1854 a implementação independente de material para a disciplina "Princípios de física e química, e introdução à história natural"78 -, poderiam até ser explicadas por sua localização açoriana e suas respectivas implicações político-administrativas, ${ }^{79}$ porém qual seria a justificativa para a omissão de outros estabelecimentos importantes cujas trajetórias igualmente remontam ao século XIX? Se o projeto consolidou de maneira única uma fonte irrefutável de identificação e valorização do patrimônio do ensino, entendido sempre em sentido amplo, muitas vezes seus limites põem em xeque o próprio rigor dos dados obtidos.

Isso não se deve apenas a ausências importantes em sua base de escolas - embora não se possa culpabilizálo de todo por elas, dado que o projeto apresentou diversas fases, que partiram da colaboração de professores das próprias instituições até ser assumido pela empresa pública Parque Escolar, ${ }^{80}$ - e aqui frisase que seu blog ${ }^{81}$ continua ativo, indiciando sua possível continuidade -, mas pelo fato de lá não se encontrarem informações específicas, por exemplo referentes à localização, à época e ao destino desses objetos, uma vez que os dados do projeto Inventário contam com instituições encerradas e remodeladas. Claro, o projeto pode responder apenas aos acontecimentos da época de sua execução, porém, tendo sido realizado concomitante com as reformas levadas à cabo pela Parque Escolar e abrangendo período considerável, algumas lacunas parecem injustificáveis.

$\bigcirc$ processo de reformas reestruturou e remodelou as edificações de diversas escolas, além de, em diversos casos, ter acompanhado igual processo de reformas legislativas e administrativas na área da educação, que configurou as escolas em
78. Cf. Beato (2011).

79. Desde 1976, os Açores representam uma região político-administrativamente autônoma, integrada na República Portuguesa.

80. Mogarro (2013, p. $85-$ 87).

81. Disponível em: <https:// bit.ly/2yuh1dI >. Acesso: $1^{\circ}$ fev. 2017. 
82. Cf. Santos (2003).

83. Cf. Diniz (2012).

84. Quando o contexto das intervenções promoveu a visita do Museu Nacional de História Natural e da Ciência (Muhnac) à Escola Secundária de Camões para o acompanhamento e apoio da reorganização de suas coleções históricocientíficas, acabou por estabelecer as bases de uma pareceria fundamental para a preservação de seu patrimônio, como atesta o parecer de Marta Lourenço disponível em: $<$ https://bit. ly/2OKoorw $>$. Acesso em: 6 fev. 2017.

85. Cf. Oliveira (2007).

86. Mogarro (2013, p. 8587). agrupamentos, de forma a unir, ao menos administrativamente, diversas escolas anteriormente autônomas e independentes. Um processo complicado em si, pois, a partir dele diversas atividades das quais se tinha notícias, nomeadamente a organização de museus nessas instituições - tal qual havia levantado e identificado Maria Paula dos Santos ${ }^{82}$-, deixaram, senão de existir por completo, de ser registradas e divulgadas, além de igualmente se perderem notícias de projetos que visavam organizar espaços similares em outras instituições de ensino levantados pela autora. E mais, há ainda relatos de que esta intervenção e remodelação danificou o patrimônio das escolas ${ }^{83}$ - mesmo que, ao trazer tais casos, seja necessário igualmente apontar outros, nos quais a consciência dos cuidados com o patrimônio surgiv exatamente de ações associadas às intervenções. ${ }^{84}$

No entanto, as questões relativas ao projeto Inventário não se restringem às imbricadas nas reformas do Parque Escolar ou à ausência de certas escolas de destacada importância histórica, pois mesmo ao analisar o levantamento e inventário do patrimônio de determinada instituição, observam-se casos que apontam para um trabalho que não foi realizado de forma extensiva, pois o número de objetos apresentados não é compatível com os dados recolhidos de outras fontes pelo projeto Patrimônio cultural luso-brasileiro, expondo assim a incompletude do levantamento. Já no início das atividades do projeto Inventário, Inês Cristina Oliveira chamava atenção para a falta de um padrão e um sistema de exatidão de dados, definição de campos de informação e terminologia adotada, propondo em sua dissertação (na área de museologia) um modelo a ser seguido. ${ }^{85}$

Some-se a isso o fato de que o próprio projeto Inventário se reconfigurou ao longo tempo, com o afastamento dos professores encarregados pela execução e treinados pelo projeto em prol de um olhar menos refinado, promovido por uma empresa voltada primordialmente à reestruturação e modernização arquitetônica, bem como pela perda do foco nas escolas industriais e nos antigos liceus históricos - e seu espólio da mesma natureza - fundados até o fim do Estado Novo, que constituíram o interesse primeiro do projeto, alargando-o de modo a incluir instituições fundadas mesmo após esta data. ${ }^{86}$ Tal incorporação nos levantamentos do passado recente se reflete também no registro de objetos de fabricação bastante recente, e que, especulativamente, podem ainda estar em uso lembora nada garanta ou indique que os mais antigos também não o estejam), fugindo mais uma vez do caráter de preocupação "histórica" original.

Ainda com todas estas graves ressalvas, o projeto Inventário permanece como a maior e mais amplamente divulgada e difundida tentativa de um levantamento do patrimônio do ensino levada a cabo em território português, ao 
menos no nível do ensino secundário. Porém não se pode deixar de mencionar que, acompanhando um interesse fomentado pela história da educação no final do século XX, iniciativas de preservação e valorização do patrimônio do ensino já começavam a aparecer em Portugal nos fins da década de 1980.87 Estas iniciativas incluíram um primeiro levantamento do patrimônio das escolas em 1989, coordenado pelos serviços do Ministério da Educação com apoio de especialistas em diferentes zonas do país, ${ }^{88}$ cujos resultados, no entanto, esta pesquisa não conseguiu obter, não havendo referência a nenhuma publicação que disponibilize seus dados.

Para os interesses deste trabalho, no entanto, nem sempre essas ações foram de todo relevantes, pois ao ter a escola em todos seus segmentos como seu objeto, verificou-se por vezes a priorização do ensino primário ou, uma vez seu escopo sendo muito mais largo que o foco de seu interesse, a exclusão ou o não aprofundamento nas áreas de interseção que levam as ações e os estudos relativos ao patrimônio do ensino a serem relevantes ao PCC\&T.

Não obstante, é necessário destacar marcos, mesmo que de vida breve, como a criação do Instituto Histórico da Educação, coordenado por António Nóvoa e que funcionou entre 1998 e 2002, o qual buscava organizar um museu ou uma rede de museus da educação, e apontou para a riqueza patrimonial sob tutela do Ministério da Educação. ${ }^{89}$ Tal riqueza foi explorada por grupos de trabalho coordenados por Nóvoa em diferentes empreitadas. Em uma apreciação do "patrimônio museológico" de liceus e escolas técnicas estes grupos constataram, como já foi observado, que 26 destes estabelecimentos possuíam um museu próprio ou em colaboração, encontrando-se tal patrimônio bem conservado e sendo de "boa qualidade". 90

Ao focar-se especificamente nas escolas secundárias originadas de antigos liceus, no entanto, Nóvoa se concentrou na questão dos arquivos, ao entender que a materialidade do patrimônio do ensino também os perpassa, tornando-se um dos responsáveis pelo projeto "Informatização normalizada dos arquivos históricos dos Liceus". $\bigcirc$ intuito deste projeto foi identificar, ordenar, reinstalar e reacondicionar, cotar, indexar, inventariar e informatizar os inventários das atuais escolas secundárias de Passos Manuel, em Lisboa, e de Sá de Miranda, em Braga, bem como informatizar os levantamentos efetuados junto dos arquivos históricos de outros 35 antigos liceus. ${ }^{91}$

Cabe ainda destacar o projeto "Educação e património cultural: um projecto sobre escolas, objectos e práticas", coordenado por Maria João Mogarro entre 2010 e 2013.92 Embora tivesse entre seus objetivos a preservação e valorização do patrimônio presente nas escolas e apresentasse diversas linhas de
87. Mogarro (2013, p. 72). 88. Mogarro (2013, p. 73). 89. Mogarro (2013, p. 72). 90. Mogarro (2013, p. 73). 91. Cf. Nóvoa e Santa-Clara (2003).

92. Cf. Mogarro (2013). 
93. Disponível em: <https:// bit.ly/2yYHsrD>. Acesso: 6 mar. 2018.

94. Cf. Couto (2012) atuação, seus resultados demonstram maior preocupação em interpretar o contexto do patrimônio do ensino pela abordagem da história da educação do que localizar, inventariar ou mesmo estudar os objetos que compõem esse patrimônio em si.

Interesse específico nos objetos de C\&T, por sua vez mais relevante ao recorte deste trabalho, foi demonstrado pelo projeto "Baú da física e da química", coordenado por Isabel Malaquias em 2004, contando com membros das Universidades de Aveiro e de Coimbra em sua participação. Este, no entanto, não apresentou caráter extensivo, tanto acerca dos estabelecimentos investigados - cuja amostragem incidia primordialmente em alguns dos liceus mais antigos, além de algumas antigas escolas técnicas, colégios e seminários espalhados pelo território português -, quanto em relação aos próprios objetos, ao buscar certos artefatos específicos, apresentando sua origem, seu funcionamento e sua utilização didática, porém não focando em um quadro mais geral da quantidade, da localização, do estado de conservação ou mesmo de informações específicas acerca da trajetória desses bens. Os próprios critérios para tais escolhas e seu recorte não eram explicitados claramente no projeto, que mantém um site apresentando seus resultados. ${ }^{93}$

Há ainda importantes iniciativas locais de preservação dos acervos desses estabelecimentos de ensino, por vezes incluídas e por vezes esquecidas pelas mencionadas tentativas maiores de mapeamento desse patrimônio. Dentre elas, podem se incluir desde iniciativas de organização de museus escolares, como a do Museu de Física da Escola Secundária Antero de Quental, que chegou a publicar uma espécie de catálogo apresentando parte de seu acervo, ${ }^{94}$ a outras menos sistemáticas e não menos importantes, como a da Escola Secundária de Camões que, mesmo não tendo ainda, até onde foi possível identificar, conseguido inventariar todo seu espólio, firmou pareceria com o Museu Nacional de História Natural e da Ciência (Muhnac) para preservar o acervo, e a da Escola Secundária Maria Amália Vaz de Carvalho que, a partir do impulso do projeto Inventário, implantou em 2009 o projeto "Inventário geral e estudo do património histórico da Escola Secundária Maria Amália Vaz de Carvalho". Este em particular, dentro do espírito proposto por este trabalho, seguiu buscando estabelecer colaborações unindo Portugal e Brasil, contexto no qual se deu a visita de Maria Lúcia Mendes de Carvalho, do Centro Paula Souza (São Paulo), à instituição.

Não se deve esquecer também dos trabalhos acadêmicos que se ocuparam de inventariar e estudar coleções específicas - nem sempre condizentes com os recortes adotados pelo projeto -, como os casos de Marcolina Guerra com as 
coleções biológicas e geológicas do antigo liceu de Portalegre latual Escola Secundária Mouzinho da Silveira), ${ }^{95}$ e de Inês Duarte Oliveira Gomes com os museus de história natural de diversos antigos liceus. ${ }^{96}$ Essas iniciativas, no entanto, revelam não apenas a variedade do que pode ser considerado patrimônio, como a variedade metodológica e do estado informacional de cada um desses projetos, com a consequente dificuldade de fazê-los dialogar entre si.

Ainda assim, foi partindo dessas empreitadas que o projeto Patrimônio cultural luso-brasileiro conseguiu, até o momento, registrar 46 entradas na categoria das Instituições de Ensino Médio (IEM), caracterizando-a como a segunda tipologia com maior número de registros em Portugal. Vale enfatizar que ainda há instituições a serem computadas, de modo que esta categoria apresenta potencial de ultrapassar os Museus (MUS), até agora com maior número de instituições registradas como detentoras de material possivelmente classificado como PCC\&T. Não por coincidência, o número de acervos classificados como MUS também conta com coleções provenientes e localizadas em instituições de ensino médio, pelo fato desta tipologia englobar os museus em escolas e todo espaço que se autodenomine "museu". Mais especificamente, catorze dos 56 museus se enquadram neste caso, o que ilustra mais uma vez o destaque das instituições de ensino médio na produção e conservação do PCC\&T em Portugal, bem como a importância do próprio patrimônio que detêm e a necessidade de conhecê-lo, inventariá-lo, e assim, também conservá-lo.

\section{CONSIDERAÇÕES FINAIS}

Como pudemos depreender dos dados apresentados, os trabalhos de levantamento e inventário realizados no Brasil e em Portugal aqui abordados se constituem como iniciativas precursoras na sistematização de importantes estoques de informação, os quais representam um recurso significativo no processo de construir conhecimentos, que por conseguinte contribuirá para uma visão mais ampla do cenário do patrimônio cultural da ciência e tecnologia.

Traçando um perfil analítico de alguns projetos de inventário do patrimônio cultural da ciência e tecnologia presentes nas escolas de ensino médio de ambos os países, identificamos a existência de um vultuoso número de trabalhos que tem a materialidade como fonte de estudo. No entanto, estes em sua maioria não enfocam a identificação, sistematização e divulgação destes estoques informacionais. 
Grande parte destes trabalhos trata-se de inventários científicos, nos quais não incidem critérios da gestão da informação, portanto o conhecimento sobre os objetos só se dá por meio de revisão bibliográfica. Nesse tipo de pesquisa, os dados sobre os objetos obedecem aos interesses de pesquisa do investigador, não disponibilizando para a comunidade acadêmica a totalidade dos dados existentes.

Com relação aos trabalhos que se dedicam diretamente a produzir estoques informacionais, há a necessidade de sistemas de localização e recuperação da totalidade de suas informações, preferencialmente utilizando metadados. Quando incompletos, tratam-se apenas de inventários de identificação que visam o reconhecimento preliminar dos objetos, também não sendo capazes de propiciar meios para garantir a salvaguarda material.

A partir dos dados levantados em ambos os países, inferimos que nenhum dos trabalhos que identificamos está devidamente sistematizado para se constituir como inventários de proteção, na medida em que não podem ser tratados como processos de valoração que sirvam de parâmetro para outras iniciativas. Para tanto, seria necessário padronização metodológica, cobertura sistemática do território e compartilhamento de repertório de dados passíveis de análise e classificação.

As metodologias das diversas iniciativas que mapeamos são diferenciadas, com padrões e recortes distintos entre si, impossibilitando a unificação dos dados recolhidos e dificultando o diálogo entre os pesquisadores e as áreas do conhecimento interessadas na temática patrimonial em geral.

Constatamos que há graves lacunas na realização de levantamentos e inventários, com amplas áreas do ensino médio com pouca ou nenhuma cobertura, a exemplo das escolas técnicas e normais, os colégios militares e de aplicação das instituições de ensino superior no Brasil. Em Portugal, cuja extensão territorial é consideravelmente menor, salta aos olhos a persistência de lacunas similares às brasileiras, com diversas instituições historicamente relevantes ausentes de levantamentos que se propõem de caráter nacional.

Os inventários produzidos não conseguem identificar as peculiaridades e os valores atribuídos aos bens culturais, como também em muitos casos não informam sobre o estado de segurança e conservação, produzindo resultados parciais que não garantem sequer uma caracterização básica do patrimônio cultural.

Cabe ainda referenciar a invisibilidade dos levantamentos e inventários já realizados, problema que acomete e une as realidades brasileira e portuguesa. Os resultados alcançados nem sempre estão amplamente disponibilizados ao público, seja por seu caráter acadêmico - em que os dados pertencem ao pesquisador - seja por 
se tratarem de dados de controle institucional, com vinculação e uso na administração interna do sistema educacional. $\bigcirc$ caráter científico/acadêmico dos levantamentos e inventários identificados, se por um lado reforça a confiabilidade dos dados produzidos, por outro dispersa a informação, dificultando sua recuperação e acessibilidade.

Essa forma de realização de inventários leva a um consequente distanciamento dos resultados obtidos, visto que os indivíduos que viveram e se envolveram com estes bens tendem a não participar de sua concepção e execução. Os inventários devem abarcar os indivíduos produtores e reprodutores das práticas sociais nas quais os bens estão inseridos, favorecendo a sensibilização da comunidade escolar.

É notável a ausência do poder público brasileiro nas políticas de preservação do patrimônio das escolas de ensino médio, assim como, de maneira geral, com todo o PCC\&T. Mesmo em Portugal a situação não é tão diferente, pois, tendo existido iniciativas governamentais importantes nessa área, geralmente tiveram vida curta, e seus dados não estão facilmente acessíveis, e por vezes até incompletos.

Diante deste quadro, compreende-se a ausência de políticas públicas de preservação deste patrimônio, pois sem dados confiáveis e padronizados não há mesmo como formular práticas preservacionistas. Conforme vários pesquisadores já alertam, as instituições de ensino médio sozinhas raramente terão interesse e/ ou recursos materiais e humanos para estabelecer tais políticas.

Apesar deste quadro aparentemente pouco favorável, a grande quantidade de dados levantados sobre os bens culturais ainda presentes nas escolas de ensino médio portuguesas e brasileiras ressalta tanto a dimensão dos acervos conhecidos quanto sua importância, indicando a necessidade do aprofundamento das pesquisas em torno dos objetos e a urgência no estabelecimento de práticas para sua conservação. Ao mesmo tempo, a falta de informação sobre os objetos que podem constituir bens culturais em escolas não mapeadas e/ou com mapeamento incompleto reforça a importância da realização de novos inventários como primeiro passo para sua preservação.

\section{AGRADECIMENTOS}

Os autores agradecem ao Conselho Nacional de Desenvolvimento Científico e Tecnológico (CNPq) pelo apoio para desenvolvimento desta pesquisa (Chamada $P Q 2013$, processo 301563/2013-6). 


\section{REFERÊNCIAS}

ALVES, Vânia Maria Siqueira. Museus escolares: um dos espaços de salvaguarda do patrimônio de ciência e tecnologia. In: GRANATO, Marcus; Ribeiro, EMANUELA Sousa; ARAÚJO, Bruno Melo (Org.). Cadernos do patrimônio da ciência e tecnologia: instituições, trajetórias e valores. Rio de Janeiro: Mast, 2017. p. 309-332.

ARAÚJO, Bruno Melo; GRANATO, Marcus. Entre o esquecer e o preservar: a musealização do patrimônio cultural da ciência e tecnologia. In: GRANATO, Marcus; RIBEIRO, Emanuela Sousa; ARAÚJO, Bruno Melo (Org.). Cadernos do patrimônio da ciência e tecnologia: instituições, trajetórias e valores. Rio de Janeiro: Mast, 2017. p. 231-254.

ARAÚJO, Bruno Melo; RIBEIRO, Emanuela Sousa; GRANATO, Marcus. Carta do patrimônio cultural de ciência e tecnologia: produção e desdobramentos. In: GRANATO, Marcus; RIBEIRO, Emanuela Sousa; ARAÚJO, Bruno Melo (Org.). Cadernos do patrimônio da ciência e tecnologia: instituições, trajetórias e valores. Rio de Janeiro: Mast, 2017. p. 11-19.

BARRETO, Aldo de Albuquerque. Os agregados de informação: memórias, esquecimento e estoques de informação. DataGramaZero, Rio de Janeiro, v. 1, n. 3, p. 01, 2000.

BEATO, Carlos Alberto Silva. O advento das ciências liceais: materialidade e programas. Diálogo Educacional, Curitiba, v. 11, n. 34, p.709-729, 2011.

BENITO, Agustín Escolano. Patrimonio material de la escuela e historia cultural. Linhas, Florianópolis, v. 11, n. 2, p. 13-28, 2010.

BRAGHINI, Katya Mitsuko Zuquim. O que os objetos científicos nos contam sobre a educação dos sentidos, na passagem do século XIX para o século XX? In: BRAGHINI, Mitsuko Zuquim; MUNAKATA, Kazami; OLIVEIRA, Marcus Aurélio Taborda (Org.). Diálogos sobre a bistória da educação dos sentidos e das sensibilidades. Curitiba: Editora da UFPR, 2017. p. 67-92.

BRAGHINI, Katya Mitsuko Zuquim; PIÑAS, Raquel Quirino; PEDRO, Ricardo Tomasiello. Museu Escolar do Colégio Marista Arquidiocesano de São Paulo: constituição, histórico e primeiros movimentos de salvaguarda da coleção. Esboços, Florianópolis, v. 21, n. 31, p. 28-49, 2014.

BRAGHINI, Katya Mitsuko Zuquim; SILVA, Camila Marchi. Museu Paulista, a instrução pública e o provimento de materiais para as escolas do estado de São Paulo: uma história dos museus escolares. In: GRANATO, Marcus; RIBEIRO, Emanuela Sousa; ARAÚJO, Bruno Melo (Org.). Cadernos do patrimônio da ciência e tecnologia: instituições, trajetórias e valores. Rio de Janeiro: Mast, 2017. p. 255-282. 
BRASIL. Decreto Ministerial de 2 de dezembro de 1837. Convertendo o Seminario de S. Joaquim em collegio de instrucção secundaria, com a denominação de Collegio de Pedro Il, e outras disposições. Colecção de Leis, Rio de Janeiro, 2 dez. 1837. p. 59-61.

Lei $\mathrm{n}^{\circ}$ 9.394, de 20 de dezembro de 1996. Estabelece as diretrizes e bases da educação nacional. Diário Oficial da União, Poder Legislativo, Brasília, DF, 23 dez. 1996. Seção 1, p. 27.833 .

Lei $\mathrm{n}^{\circ}$ 11.904, de 14 de janeiro de 2009. Institui o Estatuto de Museus e dá outras providências. Diário Oficial da União, Poder Legislativo, Brasília, DF, 15 jan. 2009. Seção 1, p. 1 .

Decreto $\mathrm{n}^{\circ}$ 8.124, de 17 de outubro de 2013. Regulamenta dispositivos da Lei $\mathrm{n}^{\circ} 11.904$, de 14 de janeiro de 2009, que institui o Estatuto de Museus, e da Lei $\mathrm{n}^{\circ} \mathbf{1 1 . 9 0 6}$, de 20 de janeiro de 2009, que cria o Instituto Brasileiro de Museus (Ibram). Diário Oficial da União, Poder Executivo, Brasília, DF, 18 out. 1996. Seção 1, p. 1.

Ministério da Cultura. Resolução Normativa $n^{\circ}$ 2, de 29 de agosto de 2014. Estabelece os elementos de descrição das informações sobre o acervo museológico, bibliográfico e arquivístico que devem ser declarados no Inventário Nacional dos Bens Culturais Musealizados, em consonância com o Decreto $\mathrm{n}^{\circ}$ 8.124, de 17 de outubro de 2013. Diário Oficial da União, Poder Executivo, Brasília, DF, $1^{\circ}$ set. 2014. Seção 1, p. 14.

CARVAlHO, Maria Lucia Mendes (Org.). Coleções, acervos e centros de memória: memórias e história da educação profissional. São Paulo: Centro Paula Souza, 2017.

CHUVA, Márcia. Por uma história da noção de patrimônio cultural no Brasil. Revista do Patrimônio Histórico e Artístico Nacional, Rio de Janeiro,v. 1, n. 34, p. 147-165, 2012. Disponível em : <http://portal.iphan.gov.br/uploads/ckfinder/arquivos/Numero\%2034.pdf>. Acesso em: 27 out. 2018.

CORRÊA, Rosa Lydia Teixeira. Cultura, material escolar e formação de professores: como disciplinar o corpo: imagens e textos. Educar em Revista, Curitiba, v. 1, n. 49, p. 183-205, 2013. Disponível em: <http://www.scielo.br/pdf/er/n49/a11n49.pdf>. Acesso em: 27 out. 2018.

COSTA, Ricardo Jorge. Resgatar a memória do futuro da escola. A Página da educação, Porto, v. 15, n. 153 , p. 1-2, 2006. Disponível em: <https://www.apagina.pt/?aba=7\&cat=153\&doc=1 1373\&mid=2>. Acesso em: 27 out. 2018.

COUTO, Bruno. Espólio do Museu de Física da Escola Secundária Antero de Quental: instrumentos de física e química. Ponta Delgada: Escola Secundária Antero de Quental, 2012. v. 1 . 
DINIZ, Aires Antunes. Museu da Escola Brotero de Coimbra: arte e ciência. In: FORO IBÉRICO DE MUSEÍSMO PEDAGÓGICO, 3.; JORNADAS CIENTÍFICAS DE LA SOCIEDAD ESPAÑOLA PARA EL ESTUDIO DEL PATRIMONIO HISTÓRICO EDUCATIVO, 5., 2012, Murcia. Atas... Murcia: Universidad de Murcia, 2012. p. 611-624.

DÓRIA, Luis Gastão d'Escragnolle. Memória histórica do Colégio Pedro II: 1837-1937: Comissão de Atualização da Memória Histórica do Colégio Pedro II. Brasília, DF: Inep, 1997.

DUARTE, Adelaide Manuela da Costa. O Museu Nacional de Ciência e Técnica no contexto da evolução da museologia das ciências: da ideia do museu à sua oficialização (1971-1976). Coimbra: Imprensa da Universidade de Coimbra, 2007.

FELGUEIRAS, Margarida Louro. Herança educativa e museus: reflexões em torno das práticas de investigação, preservação e divulgação histórica. Revista Brasileira de história da educação, Maringá, v. 11, n. 1, p. 67-92, 2011.

FISCARELLI, Rosilene Batista de Oliveira. A construção do saber sobre a utilização de objetos no ensino brasileiro. 2009. 171 f. Tese (Doutorado em Educação) - Faculdade de Ciências e Letras, Universidade Estadual Paulista “Júlio de Mesquita Filho”, Araraquara, 2009.

FUNARI, Pedro Paulo. Os historiadores e a cultura material. In: PINSKY, Carla Bassanezi. Fontes históricas. São Paulo: Contexto, 2005. p. 81-110.

GOMES, Inês Duarte Aleixo Lourenço de Oliveira. Os museus escolares de história natural: análise histórica e perspectivas de futuro (1836-1975). 2014. 929 f. Tese (Doutorado em História e Filosofia das Ciências) - Secção Autónoma de História e Filosofia das Ciências, Universidade de Lisboa, Lisboa, 2014.

GRANATO, Marcus. Panorama sobre o patrimônio de ciência e tecnologia no Brasil: objetos de C\&T. In: GRANATO, Marcus; RANGEL, Márcio Ferreira. Cultura material e patrimônio da ciência e tecnologia. Rio de Janeiro: Mast, 2009. p. 78-102.

Patrimônio cultural luso-brasileiro de ciência e tecnologia: pesquisa, análise e acessibilidade. Rio de Janeiro: Mast, 2014. (Projeto de pesquisa).

GRANATO, Marcus; SANTOS, Fernanda Pires. Os museus e a salvaguarda do patrimônio cultural de ciência e tecnologia no Brasil. In: GRANATO, Marcus (Org.). Museologia e patrimônio. Rio de Janeiro: Mast, 2015. v. 1, p. 78-119. 
GRANATO, Marcus; MAIA, Elias da Silva; SANTOS, Fernanda Pires. Valorização do patrimônio científico e tecnológico brasileiro: descobrindo conjuntos de objetos de C\&T pelo Brasil. Anais do Museu Paulista, São Paulo, v. 22, n. 2, p. 11-34, 2014.

GRANATO, Marcus et al. Valorização do patrimônio científico e tecnológico brasileiro: resultados de pesquisa. In: ENCONTRO NACIONAL DE PESQUISA EM CIÊNCIA DA INFORMAÇÃO, 14., 2013, Florianópolis. Anais... Florianópolis: UFSC, 2013. p. 1-20.

GUERRA, Marcolina João Espiguinha. Memória e materialidade no ensino liceal: um percurso pelo património e materiais didácticos do Liceu de Portalegre. 2008. 248 f. Dissertação (Mestrado em Ciências da educação) - Faculdade de Psicologia de Ciências da Educação, Universidade de Lisboa, Lisboa, 2008.

HEERING, Peter; WITTJE, Roland. An historical perspective in instruments and experiments in science education. Science E Education, Amsterdam, v. 21, n. 9, p. 151-155, 2012.

LIMA, Diana Farjalla Correia. Musealização e patrimonialização: formas culturais integradas, termos e conceitos entrelaçados. In: ENCONTRO NACIONAL DE PESQUISA EM CIÊNCIA DA INFORMAÇÃO, 15., 2014, Belo Horizonte. Anais... Belo Horizonte: UFMG, 2014. p. 4.3354.355 .

LOURENÇO, Marta. O patrimônio da ciência: importância para a pesquisa. Museologia e Patrimônio, Rio de Janeiro, v. 2, n. 1, p. 47-53, 2009.

MARINS, Paulo César Garcez. Novos patrimônios, um novo Brasil? um balanço das políticas patrimoniais federais após a década de 1980. Estudos Históricos, Rio de Janeiro, v. 29, n. 57 , p. 9-28, 2016.

MELONI, Reginaldo Alberto. A experiência de constituição de uma fonte documental a partir dos instrumentos de ensino de química e física do Colégio Culto à Ciência de Campinas/SP. Revista Brasileira de história da educação, Maringá, v. 11, n. 1 [25], p. 4365, 2011.

O patrimônio escolar do ensino das ciências na escola secundária brasileira: 1870/1910. In: CONGRESSO LUSOBRASILEIRO DE HISTÓRIA DA EDUCAÇÃO, 9., 2012, Lisboa. Atas... Lisboa: Instituto de educação da Universidade de Lisboa, 2012. p. 889-899.

. Tools for teaching physics and chemistry in secondary schools: the case of the Colégio Culto à Ciência, Brazil, 1899-1902. In: GRANATO, Marcus; LOURENÇO, Marta (Org.). Scientific instruments in the bistory of science: studies in transfer, use and preservation. Rio de Janeiro: Mast, 2014. p. 247-257. 
MELONI, Reginaldo Alberto. Limites e perspectivas na preservação dos objetos de ensino de Química de uma escola pública em São Paulo. In: Congresso Brasileiro de história da educação, VIII, 2015, Maringá. Anais... Maringá: Universidade Estadual de Maringá 2015.

MENESES, Maria de Fátima de Faria Pinto. Museus e ensino: uma análise histórica sobre os museus pedagógicos e escolares em Portugal (1836-1933). 2003. 287 f. Dissertação (Mestrado em Museologia e Patrimônio) - Faculdade de Ciências Sociais e Humanas, Universidade Nova de Lisboa, Lisboa, 2003.

MENEZES, Maria Cristina. Descrever os documentos, construir o inventário, preservar a cultura material escolar. Revista Brasileira de história da educação, Maringá, v. 11, n. 1, p. 93-116, 2011.

MOGARRO, Maria João. Patrimônio educativo e modelos de cultura escolar na história da educação em Portugal. Cuestiones Pedagógicas, Sevilha, n. 22, p. 67-102, 2013.

MOTTA, Lia; REZENDE, Maria Beatriz. Inventário. In: GRIECO, Bettina; TEIXEIRA, Luciano; THOMPSON, Analucia (Org.). Dicionário Iphan de patrimônio cultural. 2. ed. Rio de Janeiro: Iphan, 2016. p. 1-39. Disponível em: <http://portal.iphan.gov.br/dicionarioPatrimonioCultural/ detalhes/64/inventario>. Acesso em: 27 out. 2018.

NAKAMUTA, Adriana Sanajotti. A trajetória de preservação dos bens culturais móveis e integrados sob a ótica dos inventários: algumas reflexões. In: CIDADE REVELADA: ENCONTRO SOBRE PATRIMÔNIO CULTURAL, 9.; FÓRUM NACIONAL DE CONSELHOS DE PATRIMÔNIO CUlTURAL, 1., 2006, Itajaí. Anais... Itajaí: Maria do Cais, 2006. p. 1-12.

NÓVOA, António; SANTA-CLARA, Ana Teresa (Coord.). "Liceus de Portugal": histórias, arquivos, memórias. Porto: Asa, 2003.

OLIVEIRA, Inês Cristina de Sousa Cavadas. Intervenção museológica no património educativo: procedimentos para a inventariação de materiais escolares. 2007. 212 f. Dissertação (Mestrado em Museologia) - Programa de Pós-Graduação em Museologia, Universidade Lusófona de Humanidades e Tecnologias,Porto, 2007.

OLIVEIRA, Pedro Louvain de Campos. Preservação do patrimônio cultural científico e tecnológico brasileiro: legislação pertinente, identificação e análise de bens tombados. 2015. $231 \mathrm{f}$. Dissertação (Mestrado em Museologia e Patrimônio) - Programa de Pós-Graduação em Museologia e Patrimônio, Universidade Federal do Estado do Rio de Janeiro, Rio de Janeiro, 2015.

PEREIRA DA COSTA, Francisco Augusto. Anais pernambucanos, 1824-1833. Recife: Fundarpe, 1984. v. 9. 
PESSANHA, Eurize Caldas; BRITO, Silvia Helena Andrade. Ensino secundário ou educação secundária? controvérsias e singularidades na escrita de sua história. In: CONGRESSO BRASILEIRO DA HISTÓRIA DA EDUCAÇÃO, 7., 2013, Cuiabá. Anais... Cuiabá: UFMT, 2013. p. 1-15.

PETRY, Marília Gabriela; SILVA, Vera Lúcia Gaspar. Museu escolar: sentidos, propostas e projetos para a escola primária: séculos XIX e XX. História da educação, Santa Maria, v. 17, n. 41, p. 79-101, 2013.

PINHEIRO, Lena Vânia Ribeiro; GRANATO, Marcus. Para pensar a interdisciplinaridade na preservação: algumas questões preliminares. In: SILVA, Rubens Ribeiro Gonçalves (Org.). Preservação documental: uma mensagem para o futuro. Salvador: Edufba, 2012. p. 23-40.

PONTE, António. 40 anos depois de abril: património e ciência no norte de Portugal. Revista da Faculdade de Letras Ciências e Técnicas do Patrimônio, Porto, v. 13, p. 239-247, 2014.

PORTUGAL. Lei n ${ }^{\circ}$ 47, de 19 de agosto de 2004. Aprova a Lei Quadro dos Museus Portugueses. Diário da República, Lisboa, n. 195, 19 ago. 2004, p.5379-5394.

POSSAMAI, Zita Rosane. Olhares cruzados: interfaces entre história, educação e museologia. Revista Museologia e Interdisciplinaridade, v. 3, n. 6, p. 17 -32, 2015. Disponível em: <http:// periodicos.unb.br/index.php/museologia/article/download/14926/10690> Acesso em: 27 set. 2018.

POSSAMAI, Zita Rosane; PAZ, Felipe Rodrigo Contri. Pesquisar e ensinar: considerações sobre museus escolares de ciências, Brasil e Argentina. In: GRANATO, Marcus; RIBEIRO, Emanuela Sousa; ARAÚJO, Bruno Melo (Org.). Cadernos do patrimônio da ciência e tecnologia: instituições, trajetórias e valores. Rio de Janeiro: Mast, 2017. p. 283-309.

POULOT, Dominique. A compreensão do patrimônio contemporâneo e seus limites. Revista do Patrimônio Histórico e Artístico Nacional, Rio de Janeiro, v. 1, n. 36, p. 107-136, 2017. Disponível em: <http://www.academia.edu/35092364/Dominique_Poulot_A_ compreens\%C3\%A3o_do_patrim\%C3\%B4nio_contempor\%C3\%A2neo_e_seus_limites $>$. Acesso em: 27 out. 2018.

RIBEIRO, Emanuela Sousa. Inventários de bens móveis e integrados como instrumento de preservação do patrimônio cultural: a experiência do INBMI/Iphan em Pernambuco. Projeto bistória, São Paulo, v. 40, p. 71-96, jun. 2010.

SAAVEDRA, Vicente Peña; FUSTES, Emilio Castro. Les musées pédagogiques dans le monde ibérique: rétrospective et actualité. In: INTERNATIONAL SYMPOSIUM FOR SCHOOL MUSEUMS AND SCHOOL HISTORICAL, 11., 2005. Anais... Genebra, 2005. 
SANTOS, Fernanda Pires. Encontro entre a sociedade e o patrimônio de ciência e tecnologia: os objetos de ciência e tecnologia nos museus da cidade do Rio de Janeiro. 2014. $154 \mathrm{f}$. Dissertação (Mestrado em Museologia e Patrimônio) - Programa de Pós-Graduação em Museologia e Patrimônio, Universidade Federal do Estado do Rio de Janeiro, Rio de Janeiro, 2014.

SANTOS, Maria do Rosário Nogueira Pinto. O museu escolar: sentido(s) do processo museológico e da prática pedagógica. 2006. 232 f. Dissertação (Mestrado em Museologia) Programa de Pós-Graduação em Museologia, Universidade Lusófona de Humanidades e Tecnologias,Porto, 2006.

SANTOS, Maria Paula Branco Marcelino. Os museus escolares nas escolas secundárias portuguesas. Cadernos de Sociomuseologia, Lisboa, v. 24, n. 4, p. 1-385, 2003.

SILVA, Vera Lucia Gaspar; PETRY, Marilia Gabriela (Org.). Objetos de escola: espaços e lugares de constituição de uma cultura material escolar: Santa Catarina, séculos XIX e XX. Florianópolis: Insular, 2012. p. 19-24.

SOUZA, Rosa Fátima. Apresentação: vestígios da cultura material escolar. Revista Brasileira de história da educação, Maringá, v. 7, n. 2 [14], p. 11-14, maio/ago. 2007.

VIDAL, Diana Gonçalves; SILVA, Vera Lucia Gaspar. Por uma história sensorial da escola e da escolarização. Linhas, Florianópolis, v. 11, n. 2, p. 29-45, 2010.

VIDAL, Diana Gonçalves. História da educação como arqueologia: cultura material escolar e escolarização. Revista Linhas, Florianópolis, v. 18, n. 36, p. 251-272, jan./abr. 2017. Disponível em: <http://www.revistas.udesc.br/index.php/linhas/article/download/1984723818362017251/ pdf> Acesso em: 28 set 2018.

XAVIER, Ana Paula da Silva; MARQUES, Abimael Antunes. Cultura material escolar na província de Mato Grosso. In: CONGRESSO LUSO-BRASILEIRO DE HISTÓRIA DA EDUCAÇÃO, 6., 2006, Uberlândia. Anais... Uberlândia: UFU, 2006. p. 156-172.

ZANCUL, Maria Cristina de Senzi. A coleção de instrumentos antigos do laboratório de física da Escola Estadual Bento de Abreu de Araraquara. Ensaio Pesquisa em educação em Ciências, Belo Horizonte, v. 11, n. 1, p. 71-84, 2009.

Os instrumentos antigos do laboratório de física da Escola Estadual Bento de Abreu de Araraquara. In: GRANATO, Marcus; LOURENÇO, Marta (Org.). Coleções científicas lusobrasileiras: patrimônio a ser descoberto. Rio de Janeiro: Mast, 2010. p. 145-158. 
ZANCUL, Maria Cristina de Senzi. Patrimônio educativo de C\&T: objetos remanescentes nas primeiras escolas secundárias públicas do estado de São Paulo. Museologia e Patrimônio, Rio de Janeiro, v. 11, n. 1, p. 138-158, 2018.

Artigo apresentado em 03/05/2018. Aprovado em 17/09/2018

\section{(cc) BY}

All the contents of this journal, except where otherwise noted, is licensed under a Creative Commons Attribution License 